\title{
Correlation of chemical and mechanical property changes during oxidative degradation of neoprene
}

\author{
M. Celina ${ }^{a}$, J. Wise ${ }^{a}$, D. K. Ottesen ${ }^{b}$, K. T. Gillen ${ }^{a}$, and R. L. Clough ${ }^{a}$ \\ ${ }^{a}$ Sandia National Laboratories, Albuquerque, NM 87185-1407, USA \\ ${ }^{b}$ Sandia National Laboratories, Livermore, CA 94551-9403, USECEIVED \\ JUL 131999 \\ Abstract \\ OSTI
}

The thermal degradation of a commercial, stabilized, unfilled neoprene (chloroprene) rubber was investigated at temperatures up to $140^{\circ} \mathrm{C}$. The degradation of this material is dominated by oxidation rather than dehydrochlorination. Important heterogeneous oxidation effects were observed at the various temperatures investigated using infrared micro-spectroscopy and modulus profiling. Intensive degradation-related spectral changes in the IR occurred in the conjugated carbonyl and hydroxyl regions. Quantitative analysis revealed some differences in the development of the IR oxidation profiles, particularly towards the sample surface. These chemical degradation profiles were compared with modulus profiles (mechanical properties). It is concluded that the profile development is fundamentally described by a diffusion-limited autoxidation mechanism. Oxygen consumption measurements showed that the oxidation rates display non-Arrhenius behavior (curvature) at low temperatures. The current results, when compared to those of a previously studied, clay-filled commercial neoprene formulation, indicate that the clay filler acts as an antioxidant, but only at low temperatures.

Keywords: Thermal polymer degradation, rubber aging, heterogeneous degradation, FTIRmicroscopy, oxygen consumption, modulus profiling, degradation profiles, carbonyl profiles, neoprene, oxygen diffusion effects 


\section{DISCLAIMER}

This report was prepared as an account of work sponsored by an agency of the United States Government. Neither the United States Government nor any agency thereof, nor any of their employees, make any warranty, express or implied, or assumes any legal liability or responsibility for the accuracy, completeness, or usefulness of any information, apparatus, product, or process disclosed, or represents that its use would not infringe privately owned rights. Reference herein to any specific commercial product, process, or service by trade name, trademark, manufacturer, or otherwise does not necessarily constitute or imply its endorsement, recommendation, or favoring by the United States Government or any agency thereof. The views and

opinions of authors expressed herein do not necessarily state or reflect those of the United States Government or any agency thereof. 


\section{DISCLAIMER}

Portions of this document may be illegible in electronic image products. Images are produced from the best available original document. 


\section{Introduction}

The degradation of polymers often occurs as a non-uniform or heterogeneous process and it is important to consider the development of such heterogeneities to correctly interpret aging mechanisms. Considerable efforts have been devoted to study and characterize the development of heterogeneities resulting from, for example, diffusion-limited oxidation, migration of antioxidants, morphological variations within polymers, catalyst residues, and centers of isolated reaction sequences during the thermal, UV and radiation degradation of polymers.

The measurement of degradation profiles has been attempted with a variety of methods. Many of the common techniques, their limitations and applicability were summarized in a detailed review [1]. Some of the most useful and simplest approaches are modulus profiling, extensively used in the past to investigate diffusion-limited oxidation (DLO) of elastomers $[2,3,4,5]$, density profiling $[3,6,7]$, position-sensitive or imaging chemiluminescence $[8,9,10,11]$, and pinpoint dynamic mechanical analysis [12]. Although fourier transform infrared spectroscopy using microtoming of samples and microscopy equipment (FTIR-microscopy) with sufficient sensitivity and resolution has been available for some time, relatively few studies have established detailed degradation profiles using this technique $[13,14,15,16,17]$.

We are currently involved in an extensive program to study the thermal degradation of various elastomers, commonly used as seal and o-ring materials. Our earlier studies of DLO effects in thermal environments focussed on modulus profiling results $[4,5]$ and the modeling of these and similar data $[5,6]$ where it was determined that modulus increases caused by oxidation governed the mechanical property lifetimes. More recently, we combined modulus profiling with FTIR-microscopy studies on a non-carbon-black-filled nitrile rubber [18]. In this instance, it was shown that carbonyl growth correlated well with the rubber hardening, and could be described using our diffusion-limited oxidation model. Only at relatively high extents of oxidation was an additional edge effect (i.e. secondary degradation mechanism) observed; under these conditions, considerable hardening did not correspond to the same magnitude of chemical oxidation [18]. The aim of the current study is to further investigate such anomalous effects in a neoprene material by comparing 
modulus profiles with degradation profiles related to actual oxidation chemistry as determined by infrared analysis.

Because this work discusses degradation mechanisms of neoprene, we first briefly review the literature on this subject. Polychloroprene has a high chlorine content $(\sim 40 \%)$ similar to polyvinylchloride (PVC), and any thermal degradation might be expected to proceed via a combination of dehydrochlorination and simple hydrocarbon-type autoxidation reactions. Dehydrochlorination is in fact the dominant degradation mechanism for PVC at high temperatures [19], which occurs easily, since each time a double bond is formed, a reactive allylic chlorine site also forms. In polychloroprene, however, this process is not easily possible since the chlorines are mostly present as unreactive vinyl units. Based on studies of the thermal degradation of the uncrosslinked polychloroprene polymer under nitrogen, it was suggested that dehydrochlorination on the 1,4-addition product is in fact restricted [20]. Dehydrochlorination may instead proceed via reactions involving structural isomers and other irregularities [20]. The free radical polymerization of chloroprene (2-chloro-1,3butadiene) yields predominately trans-1,4-polychloroprene via 1,4-addition, but also smaller amounts of the 1,2-and 3,4-addition isomers as structural irregularities dependent on the polymerization temperature [21]. The degradation of uncrosslinked polychloroprene involving oxygen was found to proceed via allylic radical intermediates resulting in $\mathrm{HCl}$ elimination, in-chain carbonyl formation and various other hydroperoxide products [22].

The thermal degradation of the crosslinked neoprene (chloroprene) rubber [23] under oxygen should also result in oxidative chain scission, in-chain carbonyl and volatile formation, and enhanced possibilities of dehydrochlorination. However, curing of the rubber decreases the concentration of vinyl chlorines and unsaturation in the polymer and would hence reduce the potential formation of some reactive allylic intermediates. We would therefore expect less formation of structurally favored conjugated sequences and thus only limited dehydrochlorination. A more favorable free radical autoxidation may in fact be the preferred degradation mechanism. 


\section{Experimental}

\subsection{Material}

The neoprene ('chloroprene') rubber material [23] used in this study was obtained as compression-molded sheets of approximately 2-mm thickness from Burke Rubber Industries. The formulation of this neoprene rubber, a typical commercial product, commonly used to manufacture O-rings and seals, is 100 parts Neoprene GN, 5 pph zinc oxide, 4 pph magnesium oxide, 2 pph Vanox MBPC antioxidant (2,2'-methylene-bis (4methyl-6-t-butylphenol)), $1.5 \mathrm{pph}$ sulfur, $1.5 \mathrm{pph}$ Altax crosslinker (2,2'-benzothiazolyl disulfide), and $0.5 \mathrm{pph}$ stearic acid. Although this formulation does not include the common filler of $\sim 40 \%$ hard-clay [5], thereby simplifying the FTIR spectroscopic analysis (higher transmittance), it was thermally cured using the same procedure as normally applied to the filled material.

\subsection{Thermal aging}

Thermal aging of strips (approximately $6 \mathrm{~mm}$ wide and $150 \mathrm{~mm}$ long) cut from the rubber sheets ( $\sim 2-\mathrm{mm}$ thickness) was carried out in temperature-controlled $\left( \pm 1^{\circ} \mathrm{C}\right.$ stability), commercial, air-circulating aging ovens under ambient atmospheric conditions $(\sim 630$ $\mathrm{mmHg}$ in Albuquerque).

\subsection{FTIR analysis}

Our micro-spectroscopy instrumentation is based on a Biorad FTS-40 IR spectrometer with $\mathrm{XY}$-grid positioning stage $(20-\mu \mathrm{m}$ resolution), software-controlled stepper motor and a liquid-nitrogen-cooled MCT-detector [18]. Spectra were recorded in transmission mode (ratioed to an appropriate background), typically as 64 time-averaged scans with a resolution of $4 \mathrm{~cm}^{-1}$. The modulation frequency was $20 \mathrm{kHz}$ and the low pass filter was set to $4.5 \mathrm{kHz}$. IR absorbance spectra of the aged samples were obtained from cross-sectioned microtome cuttings of approximately $10-\mu \mathrm{m}$ thickness produced with a commercial microtome using liquid nitrogen cooled samples as described previously [18]. Profiles were constructed from successive spectra by scanning across a microtome specimen in increments of $100 \mu \mathrm{m}$. Quantitative oxidation profiles were obtained via internal referencing rather than using direct changes in the absorbance, due to some variations in the specimen thickness [18]. 


\subsection{Modulus profiling}

Our modulus profiler apparatus which monitors the penetration of a paraboloidally-shaped tip into a polymer sample, has been described in detail elsewhere $[1,2,4,24]$, with the exception that the current version is now completely automated [18]. Penetration data are converted to inverse tensile compliance values, which approximate the modulus. The instrument allows for convenient scanning across a sample with a resolution of approximately $50 \mu \mathrm{m}$. The rubber specimens were cut in cross-section, encapsulated in epoxy resin to improve sample handling, mounted in a custom-made clamp and then metallographically polished [2]. The modulus profile was then obtained by measuring individual modulus values across the polished cross-section of the sample. Identical profile results were obtained when using the original approach of positioning three identical samples side-by-side to enable a more precise edge modulus determination [2]. This indicates that any possible edge effects due to epoxy-encapsulation do not significantly affect the modulus measurements.

\subsection{Oxygen consumption (uptake)}

The consumption of oxygen as well as the formation of $\mathrm{CO}$ and $\mathrm{CO}_{2}$ during thermal aging was determined using a gas chromatography (GC) apparatus. Details of this approach have been described before, and the technique has been established as a simple routine analysis [25]. Known amounts of the neoprene rubber (sufficiently thin to avoid diffusion-limited oxidation) were sealed at room temperature in ampoules of known volume with an initial $\mathrm{O}_{2}$ pressure calculated to give $\sim 15 \mathrm{cmHg}$ at the relevant aging temperature. The containers were then aged for times which led to consumption of approximately $30 \%$ of the $\mathrm{O}_{2}$. This resulted in an average partial pressure during each aging exposure of $\sim 13 \mathrm{cmHg} \mathrm{O}_{2}$, which is roughly equal to ambient air conditions in Albuquerque. At each aging temperature, the same sample was used sequentially to obtain time-dependent results.

\subsection{Permeation measurements}

Oxygen permeation experiments were performed on a disk sample of approximately $64 \mathrm{~mm}$ diameter and $2 \mathrm{~mm}$ thickness using a custom-modified, commercial Oxtran-100 coulometric permeation apparatus (Modern Controls, Inc., Mineapolis, MN, USA), which is based on an ASTM standard [26]. To allow for high temperature analysis a modified sample holder was positioned in a common laboratory oven. More details on this instrumentation and its application to various materials will be published separately. 


\section{Results and discussion}

\section{1 $\mathrm{O}_{2}$ consumption and permeability measurements}

Oxygen consumption rates $(\phi)$ and $\mathrm{O}_{2}$ permeability coefficients $\left(P_{\mathrm{ox}}\right)$ are required for modeling of oxidation profiles at elevated temperatures [5]. The consumption rates are measured on samples that are sufficiently thin to avoid diffusion-limited oxidation effects during the experiment. By varying the aging time and the ratio of sample to gas volume in the ampoules, a large sensitivity range $\left(\phi \sim 10^{-13}-10^{-8} \mathrm{~mol} / \mathrm{g}-\mathrm{s}\right)$ is easily available $[25,27]$. Such sensitivity allows measurements to be made down to ambient temperature within a reasonable experimental time frame (a few months for the current neoprene material). The $\mathrm{O}_{2}$ consumption rate data obtained between $140^{\circ} \mathrm{C}$ and $25^{\circ} \mathrm{C}$ for the unfilled neoprene rubber are shown in Fig. 1. These consumption rates are essentially linear over the useful lifetime of the material at each temperature, which is in agreement with previous results for similar materials $[5,25,27]$.

The relatively high but constant oxidation rates are contrary to the school of thought arguing that thermal aging of polymers should follow the classical autoxidation mechanism $[28,29,30]$. This model describes an induction period with distinctly low oxidation rates (particularly for highly stabilized polymers), which is followed by a dramatic increase in the oxidation rate often equivalent to a sudden exponential growth in oxidation product concentration. While an induction period by definition represents a time period of essentially constant oxidation rates, it is also normally expected that the end of the induction period corresponds to low yields of oxidation products [30]. For the current material, the overall aging is essentially linear from the earliest time, but proceeds with relatively high rates despite the presence of a significant amount of a hindered-phenol antioxidant (2 pph Vanox MBPC), implying that the antioxidant is relatively ineffective in this formulation. Thus, the thermo-oxidation of this neoprene rubber is fundamentally different from that of common stabilized polyolefins (PE, PP). The presence of an antioxidant in these materials results in an induction period during which the antioxidant is consumed via very low oxidation rates, but the carbonyl yield or degradative damage is basically zero. This is normally followed by a rapid autoaccelerative increase in the carbonyl index after the end of the induction period [30]. 
Compared to the commonly used, but less sensitive pressure transducer approach [31] for measuring $\phi$, the GC method for oxygen consumption has the additional advantage that it allows for easy measurement of the evolution of other volatile oxidation products, such as $\mathrm{CO}_{2}$ and $\mathrm{CO}$ normally generated during polymer aging. [25]. Comparing the results for these two products with the $\mathrm{O}_{2}$ consumption rates reveals variations in the oxidation mechanism with temperature (Fig. 2a). The percentages of $\mathrm{CO}_{2}$ and $\mathrm{CO}$ produced per $\mathrm{O}_{2}$ consumed (Fig. 2b), increase with increasing temperature from approximately $2.5 \%$ to $11 \%$ for the yield of $\mathrm{CO}_{2}$ and $0.8 \%$ to $2 \%$ for $\mathrm{CO}$, respectively. This indicates a change in the oxidation mechanism with temperature, suggesting the increasing participation at lower temperatures of a reaction sequence that leads to reduced amounts of $\mathrm{CO}_{2}$ and $\mathrm{CO}$ or increases $\mathrm{CO} / \mathrm{CO}_{2}$ at higher temperatures. While the activation energy obtained from average rates over the high-temperature range $\left(140-80^{\circ} \mathrm{C}\right)$ for the $\mathrm{O}_{2}$ consumption is 91 $\mathrm{kJ} / \mathrm{mol}$, we calculate 93 and $103 \mathrm{~kJ} / \mathrm{mol}$ for production of $\mathrm{CO}_{2}$ and $\mathrm{CO}$, respectively. A more accurate approach to determine the temperature dependence (activation energy) of any degradation parameter is achieved by a time-temperature superposition. The advantage of this approach is that it utilizes the complete data set [25,27]. For oxygen consumption, we utilize cumulative oxidation (Fig. 3a) versus time in the analysis. We first select the lowest temperature $\left(25^{\circ} \mathrm{C}\right)$ as the reference temperature $\left(T_{\text {ref. }}\right)$. If increasing the temperature to $T$ equally accelerates all of the reactions underlying the oxidation, than the time behavior of total oxidation will be accelerated by a constant multiplicative shift factor, $a_{\mathrm{T}}$. For each higher temperature, we empirically determine the value of $a_{\mathrm{T}}$ that results in the best superposition with the data at $T_{\text {ref. }}$. Figure $3 b$ shows the superposed results for the cumulative oxidation of the neoprene material and the corresponding Arrhenius plot of the empirical $a_{\mathrm{I}}$ values is shown in Fig. 3c. The results suggest Arrhenius behavior (linear dependence of $\log a_{\mathrm{T}}$ versus inverse absolute temperature) only at the highest temperatures investigated, with an activation energy of $\sim 98 \mathrm{~kJ} / \mathrm{mol}$ for this process. A common approach would be to extrapolate the straight line through these data to make predictions for lower temperatures aging (dashed extension). This would predict considerably lower oxidation rates than are actually determined for ambient aging. We observe a reduction in the prevailing activation energy to approximately $37 \mathrm{~kJ} / \mathrm{mol}$ at the lower temperatures.

The $\mathrm{O}_{2}$ permeability coefficient $\left(P_{\text {ox }}\right)$ was determined at temperatures up to $125^{\circ} \mathrm{C}$. We determine the permeability by correcting the measured permeation data for the fraction of oxygen that is consumed in the material due to oxidation during the permeation process 
itself. This is particularly important at elevated temperatures and is achieved via an iterative process. More details on this approach will be discussed in a separate publication. Our iterative data analysis requires knowledge of the oxygen consumption rate at all temperatures and a value for $\beta$, a factor that combines rate constants, solubility and $\mathrm{O}_{2}$ partial pressure, and which essentially describes the sensitivity of oxidation rates to $\mathrm{O}_{2}$ pressure [5]. For our permeability calculations we used $\beta=0.7$, which was previously found to be applicable to a filled neoprene [5]. However, the calculations are insensitive to $\beta$ over the range of reasonable values of $\beta(0.2<\beta<2)$. The permeability data for the unfilled neoprene rubber are presented in Fig. 4. At $100^{\circ} \mathrm{C}$, we determine $P_{\text {ox }} \sim 6.0 \times 10^{-9}$ ccSTP/cm-s-cmHg. The value for the corresponding clay-filled neoprene rubber at this temperature is $\sim 2.7 \times 10^{-9} \mathrm{ccSTP} / \mathrm{cm}-\mathrm{s}-\mathrm{cmHg}$ [5], a reasonable reduction since this material contains $\sim 40 \%$ inert clay filler.

\subsection{Spectral changes in the IR}

Figure $5 \mathrm{a}$ shows the IR spectrum of the unaged neoprene material. This spectrum shows some of the characteristic features expected for neoprene materials, including the $\mathrm{C}=\mathrm{C}$ band at $\sim 1660 \mathrm{~cm}^{-1}$, multiple $\mathrm{CH}$ and $\mathrm{C}-\mathrm{C}$ bending and stretch vibrations at $\sim 1445,1431,1303$, 1202,1118 and $1001 \mathrm{~cm}^{-1}$, as well as a complex $\mathrm{C}-\mathrm{Cl}$ stretching and bending band at $\sim 825$ and $580 \mathrm{~cm}^{-1}[21,32,33]$. The thermal oxidation for a neoprene sample aged at $21 \mathrm{~d}$ at $125^{\circ} \mathrm{C}$ is shown in Fig. 5b (sample interior) and Fig. 5c (edge of sample). Oxidation leads to a considerable and broad increase in the hydroxyl $\left(\sim 3400 \mathrm{~cm}^{-1}\right)$ and conjugated carbonyl $\left(\sim 1660 \mathrm{~cm}^{-1}\right)$ regions, as expected for the autoxidation of hydrocarbon-based polymers.

Similar spectral changes during the thermal oxidation of a neoprene specimen were observed when studying the in-situ oxidation using FTIR emission at elevated temperatures [34].

A comprehensive analysis of the IR spectra revealed that the band at $825 \mathrm{~cm}^{-1}$, previously assigned to a complex $\mathrm{C}-\mathrm{Cl}$ bending vibration [33], is sufficiently stable and insensitive to thermal degradation to be suitable for internal referencing. All spectroscopic evidence available in this study, i.e. the relative stability of the band at $825 \mathrm{~cm}^{-1}$ and the lack of evidence for the development of unsaturation (expected at $\sim 1600 \mathrm{~cm}^{-1}$ ) during the aging of a sample for prolonged periods at $140^{\circ} \mathrm{C}$ under nitrogen, suggests that dehydrochlorination is not significant. Dehydrochlorination as the dominant thermal degradation mechanism for PVC [19] results in strong absorbances in the IR at $\sim 1600 \mathrm{~cm}^{-1}$ [34] due to the formation of 
unsaturation and conjugated sequences. For the oxidative degradation of the neoprene we observe a relatively broad increase in the carbonyl region with an extended tail towards $\sim 1520 \mathrm{~cm}^{-1}$ (see Fig. 5). This may include a component of some developing unsaturation, but is as easily explained by the formation of conjugated carbonyls. The absence of significant dehydrochlorination is also supported by the fact that we observe a general increase in density at the temperatures investigated; in contrast the thermal degradation of the neoprene and a polyvinylchloride sample at $190^{\circ} \mathrm{C}$ (dehydrochlorination under those conditions) results in a considerable decrease in density (elimination of relatively heavy chlorine and void formation). All aspects imply that dehydrochlorination reactions do not significantly contribute to the overall degradation of the neoprene and that the degradation process is predominately of oxidative nature under the conditions investigated. Some limited dehydrochlorination, may however, not be detectable, since it is difficult to analyze a weak spectral change in a band $\left(825 \mathrm{~cm}^{-1}\right)$ that corresponds to a very high concentration of chlorine in the polymer. The opposite applies to the carbonyl formation, as those species have relatively high absorbances and are not initially present. Selecting a stable internal reference band allows for quantitative oxidation profiles to be obtained irrespective of variations in sample transmissivities as discussed later.

An overview of the heterogeneous degradation occurring in a sample aged at $140^{\circ} \mathrm{C}$ for 8 days (where the oxidation is expected to be highly diffusion limited) is shown in Fig. 6. This three dimensional plot was created by applying a simple, linear two-point baseline correction to all spectra (individual positions) yielding zero absorbance at 2000 and constant absorbance at $825 \mathrm{~cm}^{-1}$. This is necessary to compensate for fluctuations in the baselines of individual spectra due to changes in instrumental background or overall absorbance levels, and for variations in sample thickness. Preferential oxidation occurs near the air-exposed sample surface (relative sample positions 0 and 1), as evidenced by the two main oxidation band regions [i.e. hydroxyl $\left(\sim 3400 \mathrm{~cm}^{-1}\right)$ and conjugated carbonyl $(\sim 1660$ $\left.\mathrm{cm}^{-1}\right)$ ]. The observation of strong absorbances in the hydroxyl region (see Fig. 6) occurs to a larger extent than was previously observed for a nitrile rubber material [18] and suggests the formation of some or all of the following: alcohols, hydroperoxides, acids and peracids. Contrary to the continuing increase in the carbonyl bands towards the sample edges, the hydroxyl intensity tends to level off at the surface. However, the relative distribution of individual carbonyl components (i.e. major bands at $1790,1714,1630 \mathrm{~cm}^{-1}$ ) appears to be 
rather uniform throughout the sample, suggesting an oxidation mechanism for these species for which the distribution of carbonyl products does not depend on oxygen concentration.

Infrared degradation profiles of samples aged for 21 days at $125^{\circ} \mathrm{C}$ and 8 days at $140^{\circ} \mathrm{C}$ (conditions corresponding to extensive oxidation and hardening) were obtained by plotting the relative absorbance $(A)$ of the two major oxidation bands at each analyzed position (Figs. $7 \mathrm{a}$ and $\mathrm{b})$. This was achieved by integrating the carbonyl $\left(A_{\text {carbonylj }} ; 1510-1840 \mathrm{~cm}^{-1}\right)$ and hydroxyl $\left(A_{\text {hydroxyl; }} ; 3060-3750 \mathrm{~cm}^{-1}\right)$ band regions and ratioing the resulting band areas to a reference band area $\left(A_{825 \mathrm{~cm}^{-1}} ; 732-933 \mathrm{~cm}^{-1}\right)$ of each individual absorbance spectrum. We did not subtract the corresponding band areas of the original (unaged) material. The required large integration region for the carbonyl band is due to the presence of a strong band at $1660 \mathrm{~cm}^{-1}$ in the original material and the growth of dominant bands at $1630 \mathrm{~cm}^{-1}$ (conjugated carbonyls) and $1714 \mathrm{~cm}^{-1}$. With simple curve fitting routines we were not able to accurately deconvolute this broad carbonyl region and determine the individual growth of the two main carbonyl bands. As shown in Figs. $7 \mathrm{a}$ and $7 \mathrm{~b}$, respectively, there is a reasonable correlation between the relative profile shapes for the carbonyl and hydroxyl oxidation bands, except for the tendency for the hydroxyl band to level off (form shoulders) near the surface (particularly in Fig. 7b). In some samples we found the carbonyl band to reach saturation and the hydroxyl intensity to actually decrease in the immediate vicinity of the sample surface. The observation of similar profiles for the two oxidation bands by this simple superposition would immediately suggest that the total oxidation product distribution is largely independent of the extent of oxidation and appears to be governed primarily by the oxygen availability at a particular location within the sample (diffusionlimited oxidation).

\subsection{Chemical degradation profiles and modeling}

In Figs. 8a-c we present the carbonyl profiles $\left(A_{\text {carbonyl }} / A_{825 \mathrm{~cm}^{-1}}\right)$ of the neoprene rubber samples versus aging time at temperatures of $140^{\circ} \mathrm{C}, 125^{\circ} \mathrm{C}$ and $100^{\circ} \mathrm{C}$. These profiles display the features of a diffusion-limited oxidation: initially the profiles are relatively homogeneous, but strong heterogeneity develops with aging. At the highest temperature of $140^{\circ} \mathrm{C}$ (Fig. 8a), we observe heterogeneity in the oxidation from the earliest aging times, and a rapid increase in the carbonyl concentration primarily in the outer regions of the sample. The interior region is virtually unchanged, although there is a small difference 
between the original material ${ }^{\prime}$ and all aged specimens (discussed in more detail in section 3.6). The heterogeneity at the lower aging temperatures of $125^{\circ} \mathrm{C}$ and $100^{\circ} \mathrm{C} \mathrm{(Fig.} 8 \mathrm{~b}$ and $8 c$ ) is less pronounced, due to reduced diffusion limitation. The experimental data (individual data points) have been fitted with modeled carbonyl profiles (solid curves).

The modeling of diffusion limited oxidation (DLO) profiles requires knowledge of a number of parameters with respect to temperature and time, the most important of which are the oxygen consumption rate ( $\phi$ ) under equilibrium conditions (non-DLO), the oxygen permeability coefficient $\left(P_{\mathrm{ox}}\right)$, and a rate constant $\left(k_{\mathrm{air}}\right)$ describing the growth in a material property at the edge. Other parameters required are $L$ (sample thickness), $p_{\text {ox }}$ (oxygen partial pressure surrounding the sample), $k_{\text {iner }}$ (inert aging component, in our case equals zero), as well as $\rho$ (density), $\beta$ and $n$ (sensitivity of consumption rate on partial pressure and permeability on hardening; see reference [5] for discussion). The dependence of the predicted profiles on $\beta$ and $n$ is relatively weak. We applied our previously-developed model [5] to predict the degradation profiles for three temperatures $\left(p_{\mathrm{ox}}=13.2 \mathrm{cmHg}\right.$ in Albuquerque, $L=2 \mathrm{~mm}$ and $\rho=1.31 \mathrm{~g} / \mathrm{cm}^{3}$ ) using the following data, presented in Table 1 .

\begin{tabular}{|c|c|c|c|c|}
\hline $\begin{array}{c}\mathrm{T} \\
\left.{ }^{\circ} \mathrm{C}\right]\end{array}$ & $\begin{array}{c}\phi \\
{[\mathrm{mol} / \mathrm{g}-\mathrm{s}]}\end{array}$ & $\begin{array}{c}P_{\text {ox }} \\
{[\mathrm{ccSTP} / \mathrm{cm}-\mathrm{s}-\mathrm{cmHg}]}\end{array}$ & $\beta$ & $n$ \\
\hline 140 & $3.2 \times 10^{-9}$ & $1.3 \times 10^{-8}$ & 0.7 & 0.1 \\
\hline 125 & $1.2 \times 10^{-9}$ & $1.0 \times 10^{-8}$ & 0.7 & 0.15 \\
\hline 100 & $1.9 \times 10^{-10}$ & $6.0 \times 10^{-9}$ & 0.7 & 0.25 \\
\hline
\end{tabular}

Table 1: Parameters used to model diffusion limited oxidation profiles.

The required edge rate coefficients for this modeling (as well as for the hydroxyl) were individually obtained from a $2^{\text {nd }}$ order polynomial fit (see below for further discussion) for each temperature. The resulting model carbonyl profiles, shown as the solid curves on Figs. 8a-c, clearly match the experimental data. Using identical theory parameters (Table 1) the modeling results (solid curves) for the hydroxyl profiles $\left(A_{\text {hydroxyl }} / A_{825 \mathrm{~cm}^{-1}}\right)$ are compared to experimental hydroxyl results in Figs. 9a-c. Although the overall behavior is again consistent with DLO, we notice a tendency for the measured hydroxyl absorbances near the

\footnotetext{
${ }^{1}$ Note: The carbonyl measurement of the unaged material does not represent a true profile analysis. Rather, it was taken as an average of a few samples with wider cross-section to compensate for tiny variations in the original material (curing and preoxidation during manufacturing).
} 
surfaces to be lower than would be predicted by the modeled profiles. This is similar to the behavior observed in Fig. 7. Since this was not observed for the carbonyl data, it suggests a mechanistic variation affecting the hydroxyl formation towards the sample edges. Based on the reasonable overall correlation between experimental data and modeling we conclude that the development of the chemical oxidation profiles is in agreement with diffusionlimited oxidation.

At the surface of the sample, oxidation is at equilibrium, unaffected by diffusion effects. Therefore, the time-dependent changes in the relative carbonyl and hydroxyl concentration at the sample surface can be used for a time-temperature superposition at a reference temperature of $100^{\circ} \mathrm{C}$ to extract the activation energy for these reactions. The data at each temperature were multiplied by a constant factor $\left(a_{\mathrm{r}}\right)$ chosen to give the best overlap with the reference temperature data, resulting in the superposed data shown in Fig. 10. We found a good fit for these data by applying a $2^{\text {nd }}$-order polynomial description (solid curves). This relationship describes the growth in the surface carbonyl (Fig. 10a) and hydroxyl (Fig. 10b) as a function of total oxidation (time) at the $100^{\circ} \mathrm{C}$ reference temperature. Plotting the corresponding shift factors $\left(a_{\mathrm{T}}\right)$ on an Arrhenius diagram yields activation energies of 108 $\mathrm{kJ} / \mathrm{mol}$ for the surface carbonyl and $107 \mathrm{~kJ} / \mathrm{mol}$ for the hydroxyl development, as shown in Fig. 11.

Considering the earlier observation (Fig. 1) that the oxygen consumption is essentially constant over the entire degradation history, we would expect a linear dependency in the time development of surface carbonyl and hydroxyl absorbances. There is no theoretical justification for the second order polynomial fit; we use it solely because it fits these data sets better than does a linear relationship. This does not preclude successful modeling however, because the model does not require any specific functionality to establish the time dependence of a surface property of interest [5]. We can not explain why the data seem to increase somewhat faster than linearly with time. It is possible that this phenomenon results from noise in the data or there may be more hydroperoxide formation (weak absorbance in the IR) during the early stages of the degradation and thus relatively less production of carbonyl/hydroxyl (strong absorbance) functionalities. At the later stages those species may then become more dominant which would lead to a limited curvature in their development with time. Alternatively, the oxidation rate may accelerate moderately in the top layers of 
the sample due to a possible loss of antioxidant. For an unfilled nitrile rubber the carbonyl formation at the sample surface was recently shown to be a linear function of time [18].

\subsection{Changes in oxidation chemistry}

While the overall development of the oxidation profiles is governed by diffusion-limited oxidation, we observe some deviations from the expected profiles towards the sample surface. This may indicate some competition between the carbonyl and hydroxyl formation at the edges. A plot of the hydroxyl to carbonyl ratio (h/c-ratio in arbitrary units) demonstrates this in more detail (Fig. 12). Most importantly, we observe a general increase in the $\mathrm{h} / \mathrm{c}$-ratio with aging (chemical conversion) at all temperatures. This ratio is positiondependent (diffusion-limited conversion at 125 and $140^{\circ} \mathrm{C}$ ), and also appears to depend to some degree on temperature, which is evident when comparing the carbonyl (Fig. 8) and $\mathrm{h} / \mathrm{c}$-ratio plot (Fig. 12). For the longest-aged (28w) sample at $100^{\circ} \mathrm{C}$ there is a carbonyl absorbance of approximately 4.5 units throughout the material that corresponds with an arbitrary $\mathrm{h} / \mathrm{c}$-ratio of approximately 3.1 . While most of a sample aged at $140^{\circ} \mathrm{C}$ for $8 \mathrm{~d}$ and at $125^{\circ} \mathrm{C}$ for $27 \mathrm{~d}$ has a carbonyl absorbance of less than 4.5 we observe, however, a h/c-ratio of clearly more than the expected maximum value of 3.1. We conclude that in the interior of the sample the $\mathrm{h} / \mathrm{c}$-ratio increases with extent of oxidation and temperature. At the immediate edge for the severely aged samples at $140^{\circ} \mathrm{C}$ and $125^{\circ} \mathrm{C}$, however, this general trend reverses and the $\mathrm{h} / \mathrm{c}$-ratio decreases significantly. When comparing the development of carbonyl (Fig. 8) and hydroxyl (Fig. 9) profiles as well as h/c-ratios (Fig. 12) at the edges we conclude that the reduced $\mathrm{h} / \mathrm{c}$ ratio results primarily from the decrease in the hydroxyl band. This demonstrates some changes in the predominant oxidation mechanism across the sample.

\subsection{Modulus profiles}

The measured modulus profiles (individual data points) at the indicated times are shown in Figs. 13a-c. The results again indicate strong DLO effects, consistent with the time development of the carbonyl and hydroxyl profiles, as discussed above. In addition, we observe a strong edge effect, particularly at $140^{\circ} \mathrm{C}$, with higher than expected moduli at the immediate surface. Ignoring these unusual surface deviations, we chose edge values (shown as time-temperature superposed results on Fig. 14) for modeling that resulted in a good fit through the majority of the sample (solid curves on Fig. 13a-c). Given the exponential form of the results shown in Fig. 14, we describe the growth in the surface modulus $M$ as $\ln M=$ 
$k_{\text {air,modulus }}{ }^{*} t+c$ (with $k_{\text {air,modulus }}$ values of $0.315 \mathrm{~d}^{-1}$ at $140^{\circ} \mathrm{C}, 0.115 \mathrm{~d}^{-1}$ at $125^{\circ} \mathrm{C}$ and $9.56 \times 10^{-3} \mathrm{~d}^{-1}$ at $100^{\circ} \mathrm{C}$ ) and an initial step change in the modulus (post-curing effect) $c=1.7$ $\mathrm{MPa}$. The corresponding time-temperature superposition (Fig. 14) results in an activation energy of $113 \mathrm{~kJ} / \mathrm{mol}$ for the "equilibrium" surface modulus (Arrhenius plot included in Fig. 11). It is of interest to note that the modulus, a mechanical property, changes exponentially with time, while the chemical properties (e.g., carbonyl and hydroxyl data) develop with a $2^{\text {nd }}$ order polynomial function of time.

The similar activation energies observed for the chemical changes (carbonyl and hydroxyl, 108 and $107 \mathrm{~kJ} / \mathrm{mol}$ ), as well as for the modulus development of $113 \mathrm{~kJ} / \mathrm{mol}$ (disregarding the edge effect) suggest a closely related common diffusion-limited oxidation mechanism for most of the material. The edge modulus (which corresponds to a higher activation energy) is clearly affected by a secondary mechanism. This additional hardening is presumably due to a non-oxidative crosslinking mechanism, and may involve other functionalities such as unsaturation. A similar edge effect with evidence for a reduction in double bonds (resulting in additional hardening) was previously observed for a nitrile rubber [18].

\subsection{Highly diffusion-limited and inert aging}

The carbonyl and hydroxyl data for the samples aged at $140^{\circ} \mathrm{C}$ (Fig. 8a and Fig. 9a) clearly show an absorbance increase in the interior of the material. A limited growth is also observed for the modulus measurements (see Fig. 13a). Although the oxidation is highly diffusion-limited at this temperature, there is a measurable formation of oxidation products and hardening in the center. This is consistent with the modeling of the degradation which predicts some minor oxidation in the interior. The corresponding spectral changes in the center of samples aged at $140^{\circ} \mathrm{C}$ ( 4 and 8 days) are shown in Fig. 15a. We also investigated the possibility of an inert aging process resulting in similar spectral changes as observed for the oxidative process. Samples of the neoprene rubber were sealed in ampoules, filled with nitrogen, and thermally aged at elevated temperatures. The infrared analysis of these samples ( 8 days at $140^{\circ} \mathrm{C}$ and 24 days at $125^{\circ} \mathrm{C}$ ) conclusively showed (Fig. $15 \mathrm{~b}$ ) that any true inert aging, as expected, does not lead to the formation of bands in the carbonyl region. We also note that there is no increase in absorbance at $\sim 1630 \mathrm{~cm}^{-1}$ which shows that conjugated sequences due to dehydrochlorination are not being formed under those conditions. Any $\mathrm{HCl}$ elimination would thus require initial oxidative damage. 


\subsection{Summary of activation energies and Arrhenius analysis}

Of further interest is to compare the aging characteristics of the unfilled neoprene rubber with that of the corresponding clay-filled material investigated earlier [5,25]. A high clay content $(\sim 40 \%)$ limits detailed IR analysis due to its strong absorbance. Consequently, the two materials cannot be easily compared by studying the growth in chemical oxidation, but comparisons can be made for oxygen uptake rates and modulus profiling results. Both of the latter properties allow for kinetic rate constants to be evaluated and provide for a direct comparison of the two materials. The determined activation energies are summarized in Table 2.

\begin{tabular}{|l|c|c|}
\hline & \multicolumn{2}{|c|}{ Activation energies [kJ/mol] } \\
\hline \multicolumn{1}{|c|}{ Measured property } & $\begin{array}{c}\text { Unfilled } \\
\text { neoprene rubber }\end{array}$ & $\begin{array}{c}\text { Clay-filled neoprene } \\
\text { rubber [25] }\end{array}$ \\
\hline Elongation e/e & - & 90 \\
\hline Edge modulus & 113 & 92 \\
\hline $\mathrm{O}_{2}$ consumption superposition & $98-37$ (low T) & 91 \\
\hline $\mathrm{CO}_{2}$ formation rate & 92 & 91 \\
\hline CO formation rate & 103 & - \\
\hline IR-carbonyl & 108 & - \\
\hline IR-hydroxyl & 107 & - \\
\hline
\end{tabular}

Table 2: Activation energies for neoprene rubber degradation. Errors are $\sim \pm 8 \mathrm{~kJ} / \mathrm{mol}$.

The filled neoprene appears to be governed by a common activation energy whereas, for the unfilled material, we determined activation energies ranging from 92 to $113 \mathrm{~kJ} / \mathrm{mol}$ (higher temperature range). On average, the activation energies characterizing the degradation of the unfilled neoprene rubber $(104 \pm 8 \mathrm{~kJ} / \mathrm{mol})$ are slightly larger than those for the filled material $(91 \pm 8 \mathrm{~kJ} / \mathrm{mol})$. This indicates that the hard-clay filler may have a limited influence on the observed property changes and the degradation mechanism of the rubber. The consumption rates of the two materials are very similar as shown in the Arrhenius plot of the two data sets (Fig. 16a). The data for the filled material have been corrected to account for the $40 \%$ filler content (data from Table 3 and Fig. 9 of ref. [5]). It is interesting to note that the unfilled material oxidizes much faster at room temperature (RT). It appears that the filler offers a protective effect, but only near ambient temperatures, a startling conclusion only available from the ultrasensitive $\mathrm{O}_{2}$ consumption measurements. This apparent transition to a new oxidation mechanism, which becomes important near RT, may 
be related to the observed changes for the yield of $\mathrm{CO}_{2}$ and $\mathrm{CO}$ (Fig. 2b). A comparison of the modulus results (Fig 16b) is more difficult, since the two materials have very different initial hardness values and the absolute degradative changes could hence be materialspecific. In our previous studies on differences between a carbon-black-filled and unfilled nitrile rubber we also observed some degradation differences dependent on the carbon black filler $[5,18]$. The current results indicate that the hard-clay filler in the neoprene apparently can act as an antioxidant but only at the lower temperatures, which are, however, most important for life-time prediction attempts.

We conclude that the degradation of the unfilled neoprene rubber is described by a range of activation energies $(\sim 98-113 \mathrm{~kJ} / \mathrm{mol})$ for all properties investigated. Some differences in these individual parameters (i.e. modulus, carbonyl, $\mathrm{O}_{2}$ consumption) are expected and not unusual, since the degradation is a complex mixture of various oxidation reactions that should exhibit different activation energies (discussed in more detail in ref. [27]). It is, however, experimentally difficult to distinguish between individual oxidation reactions and to precisely monitor them. Thus the average rates are more easily accessible and often used (i.e. oxygen consumption or carbonyl index). We do, however, expect the different reactions to have varying importance with regard to temperature. Some reactions may only be important in one temperature regime. This can lead to curvature in the often expected linear Arrhenius diagram of a particular property. The one property with the highest sensitivity and dynamic range is oxygen consumption (Figs. 1-3). The results for this parameter follow Arrhenius behavior at high temperatures but display curvature at the lower temperatures (Fig 3c). This indicates a much faster oxidation than would be predicted from high temperature extrapolations, clearly suggesting a mechanistic change at lower temperatures. Similar behavior has now been demonstrated for several different materials $[27,35]$. It is apparent that, based on the nature of such curvatures (faster than expected oxidation rates at the lower temperature), it is easily possible to overestimate the stability of polymeric materials when using a linear extrapolation in an Arrhenius diagram.

\section{Conclusion}

The oxidative thermal degradation of a commercial, stabilized, non-clay-filled neoprene (polychloroprene) material was studied at temperatures ranging from ambient to $140^{\circ} \mathrm{C}$. Considerable temperature-dependent heterogeneous degradation effects occur at the higher temperatures, due to important diffusion-limited oxidation effects. Infrared micro- 
spectroscopy was found to be well suited to obtain position-dependent absorbance spectra by scanning across microtome cuttings of the aged neoprene samples. The degradation resulted in strong spectral changes in the carbonyl and hydroxyl regions. An internal reference band was used to enable the construction of spatial degradation profiles for the two oxidation band areas, which were found to differ in relative intensity, particularly towards the sample edges. The results also indicate that dehydrochlorination reactions do not significantly contribute to the overall degradation, which is primarily oxidative at the conditions investigated. This may be directly related to the presence of mostly vinyl chlorines with low reactivity, in contrast to $\mathrm{PVC}$, which forms reactive allylic chlorine intermediates as it undergoes double bond formation via dehydrohalogenation. It is also contrary to some published results showing dehydrochlorination for oxidative degradation of uncrosslinked polychloroprene [22].

The spatial profiles of the actual oxidation chemistry (carbonyl and hydroxyl formation) were compared with modulus profiles, which are related to changes in mechanical properties. A kinetic evaluation of the degradation profiles, by analyzing the changes at the sample surface, shows an unexpected polynomial increase in the carbonyl and hydroxyl formation and an approximately exponential rise in the edge modulus with time. A mechanistic variation appears to result in a limited surface effect for the most severely aged samples, as supported by relatively low hydroxyl absorbances, changes in the hydroxyl/carbonyl ratios, and higher moduli. The overall development of the time- and temperature-dependent degradation profiles was shown to be consistent with a model based on diffusion-limited oxidation. Low temperature oxygen consumption results indicate that the oxidation of the unfilled neoprene at room temperature proceeds faster than would be predicted from high-temperature results, as evidenced by significant curvature in the corresponding Arrhenius diagram. Comparison with a clay-filled material indicates that the clay filler may act as a limited antioxidant at low temperatures.

\section{Acknowledgments}

We thank Howard Johnsen for assistance with the FTIR equipment, Christie Graham for support with some of the measurements, and Burke Rubber Industries for providing the rubber material. Sandia is a multiprogram laboratory operated by Sandia Corporation, a Lockheed Martin Company, for the United States Department of Energy under Contract DE-AC04-94AL85000. 


\section{References}

[1] Gillen, K. T., Clough, R. L., in Handbook of Polymer Science and Technology 2, ed. N. P. Cheremisinoff, Marcel Dekker, 1989, p. 167

[2] Gillen, K. T., Clough, R. L., Quintana, C. A., Polym. Deg. Stab., 1987, 17, 31

[3] Mattson, B., Stenberg, B., Gillen, K. T., Clough, R. L., Östman, E., Polym. Deg. Stab., 1993, 41, 211

[4] Clough, R. L.; Gillen, K. T., Polym. Deg. Stab., 1992, 38, 47

[5] Wise, J., Gillen, K. T., Clough, R. L., Polymer, 1997, 38, 1929

[6] Gillen, K. T., Clough, R. L., Polymer, 1992 , 33, 4358

[7] Gillen, K. T., Clough, R. L., Dhooge, N. J., Polymer, 1986, 27, 225

[8] Ahlblad, G., Stenberg, B., Terselius, B., Reitberger, T., Polym. Test., 1997, 16, 59

[9] Fleming, R. H., Craig, A. Y., Polym. Deg. Stab., 1992, 37, 173

[10] Celina, M., George, G. A., Lacey, D. J., Billingham, N. C., Polym. Deg. Stab., 1995, 47,311

[11] Lacey, D. J., Dudler, V., Polym. Deg. Stab., 1996, 51, 101

[12] Dole, P., Chauchard, J., Polym. Deg. Stab., 1995, 47, 441

[13] Xavier, J., Adam, C., Fromageot, D., Gardette, J., Lemaire, J., Polym. Deg. Stab., $1989,25,247$

[14] Xavier, J., Gardette, J., J. Polym. Sci. A Polym. Chem., 1991, 29, 685

[15] Hoekstra, H. D., Spoormaker, J. L., Breen, J., Audouin, L., Verdu, J., Polym. Deg. Stab., 1995, 49, 251

[16] Hoekstra, H. D., Spoormaker, J. L., Breen, J., $18^{\text {th }}$ Int. Conf. Adv. Stab. Deg. Polym., Lucerne, Switzerland, 1996, 101

[17] Costa; L., Luda, M. P., Brach del Prever, E. M., 18th Int. Conf. Adv. Stab. Deg. Polym., Lucerne, Switzerland, 1996, 41

[18] Celina, M., Wise, J., Ottesen, D. K., Gillen, K. T., Clough, R. L., Polym. Deg. Stab., 60 (1998) 493 
[19] McNeill, I. C., in Comprehensive Polymer Science, Vol. 6., Chapter 15, Pergamon Press, 1989, p. 451

[20] Miyata, Y., Atsumi, M., J. Polym. Sci. Polym. Chem., 1988, 26, 2561

[21] Coleman, M. M., Petcavich, R. J., Painter, P. C., Polymer, 1978, 19, 1243

[22] Bailey, H. C., Rev. Gen. Caoutch. Plast., 1967, 44(12), 1495

[23] Neoprene, Kirk-Othmer Encycl. Chem. Technol., 3rd. ed., 1979, 8, 515

[24] Gillen, K. T., Clough, R. L., Polym. Eng. Sci., 1989, 29, 29

[25] Wise, J., Gillen, K. T., Clough, R. L., Polym. Deg. Stab., 1995, 49, 403

[26] ASTM Standard D3985-81, Oxygen Gas Transmission Rate through Plastic Film and Sheeting Using a Coulometric Sensor.

[27] Gillen, K. T., Celina, M., Clough, R. L., Wise, J., Trends in Polymer Science, 1997, 5,250

[28] Reich, L., Stivala, S., Autoxidation of hydrocarbons and polyolefins, M. Dekker, New York, 1969

[29] Allen, N. S., Degradation and Stabilization of Polyolefins, Applied Science Publishers, London, 1983

[30] Grassie, N., Scott, G., Polymer Degradation \& Stabilization, Cambridge University Press, 1985, p. 86

[31] Scheirs, J., Bigger, S. W., Billingham, N. C., Polym. Test., 1995, 14, 211

[32] Tabb, D. L., Koenig, J. L., J. Polym. Sci. Polym. Phys., 1975, 13, 1159

[33] Wallen, P.J., Spectrochimica Acta, 1991, 47, 1321

[34] Celina, M., Ottesen, D. K., Gillen, K. T., Clough, R. L., Polym. Deg. Stab., 1997, 58,15

[35] Celina, M., Graham, A. C., Minier, L. M., Gillen, K. T., Clough, R. L., Polym. Deg. Stab., submitted 


\section{Figures}

Fig. 1 Oxygen consumption data for the unfilled neoprene rubber.

Fig. 2 a) Arrhenius plot of the oxygen consumption rate, and $\mathrm{CO}_{2}$ and $\mathrm{CO}$ production rates of the unfilled neoprene rubber, b) $\mathrm{CO}_{2}$ and $\mathrm{CO}$ formation as a percentage of $\mathrm{O}_{2}$ consumption.

Fig. 3 a) Integrated oxygen consumption, b) superposition of consumption and c) Arrhenius plot of the superposition shift factors $\left(a_{\mathrm{T}}\right)$.

Fig. 4 Oxygen permeability measurements.

Fig. 5 Spectral growth in the carbonyl and hydroxyl regions for thermally aged neoprene rubber samples. a) unaged material, b) aged 21 days at $125^{\circ} \mathrm{C}$ (sample interior) and c) aged 21 days at $125^{\circ} \mathrm{C}$ (sample edge).

Fig. 6 3D presentation of the FTIR absorbance profile of an unfilled neoprene rubber sample aged for 8 days at $140^{\circ} \mathrm{C}$.

Fig. 7 Oxidation profiles obtained for the carbonyl and hydroxyl bands of a neoprene rubber sample aged for a) 21 days at $125^{\circ} \mathrm{C}$ and b) 8 days at $140^{\circ} \mathrm{C}$.

Fig. 8 Carbonyl profile development of the unfilled neoprene rubber aged at a) $140^{\circ} \mathrm{C}$, b) $125^{\circ} \mathrm{C}$ and c) $100^{\circ} \mathrm{C}$ fitted with predicted degradation profiles.

Fig. 9 Hydroxyl profile development of the unfilled neoprene rubber aged at a) $140^{\circ} \mathrm{C}$, b) $125^{\circ} \mathrm{C}$ and c) $100^{\circ} \mathrm{C}$ fitted with predicted degradation profiles.

Fig. 10 Empirical time-temperature superposition of the growth in the relative surface concentration of a) carbonyl and b) hydroxyl data (corresponding Arrhenius plot of the $a_{\mathrm{T}}$ factors in Fig. 11).

Fig. 11 Arrhenius plot of the $a_{\mathrm{T}}$ factors for the changes in carbonyl, hydroxyl and modulus values.

Fig. 12 Ratio of hydroxyl to carbonyl absorbance versus cross-sectional position for the unfilled neoprene rubber aged at a) $140^{\circ} \mathrm{C}$, b) $125^{\circ} \mathrm{C}$ and c) $100^{\circ} \mathrm{C}$.

Fig. 13 Modulus profile development of the unfilled neoprene rubber aged at a) $140^{\circ} \mathrm{C}, \mathrm{b}$ ) $125^{\circ} \mathrm{C}$ and c) $100^{\circ} \mathrm{C}$ fitted with predicted degradation profiles. 
Fig. 14 Empirical time-temperature superposition of the surface moduli growth at $T_{\text {ref }}=$ $100^{\circ} \mathrm{C}$ (corresponding Arrhenius plot of the $a_{\mathrm{T}}$ factors in Fig. 11).

Fig. 15 Spectral changes in the carbonyl and hydroxyl regions in the interior of samples aged at a) $140^{\circ} \mathrm{C}$ ( 4 and 8 days) under normal atmosphere and b) at $140^{\circ} \mathrm{C}$ ( 8 days) and $125^{\circ} \mathrm{C}$ (24 days) under nitrogen.

Fig. 16 Arrhenius plots for the unfilled neoprene rubber in comparison with the corresponding clay-filled material of the a) oxygen uptake rates (per gram of polymer) and b) surface modulus growth rates $\left(k_{\mathrm{air}}\left[\mathrm{d}^{-1}\right]\right)$. 


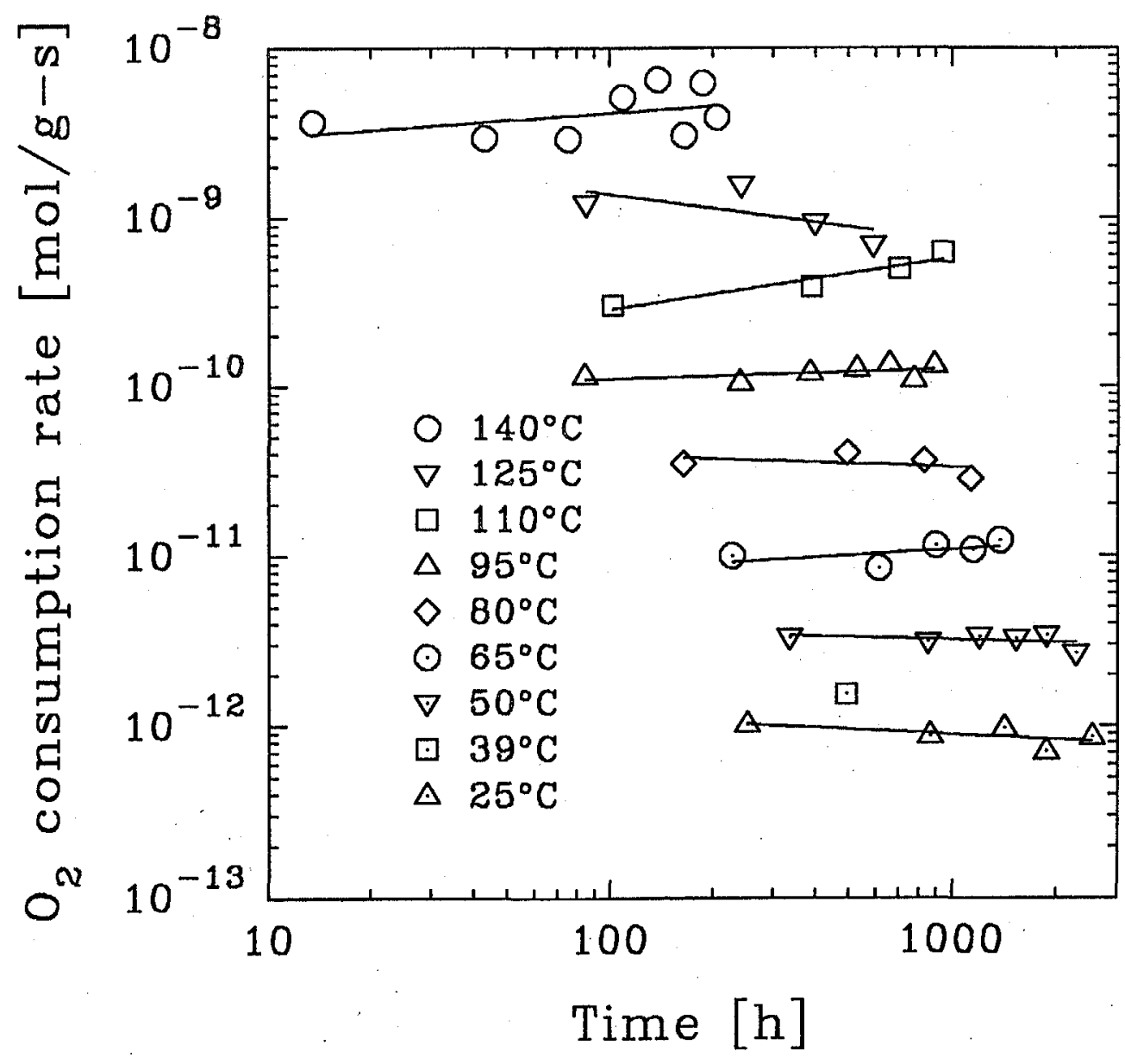




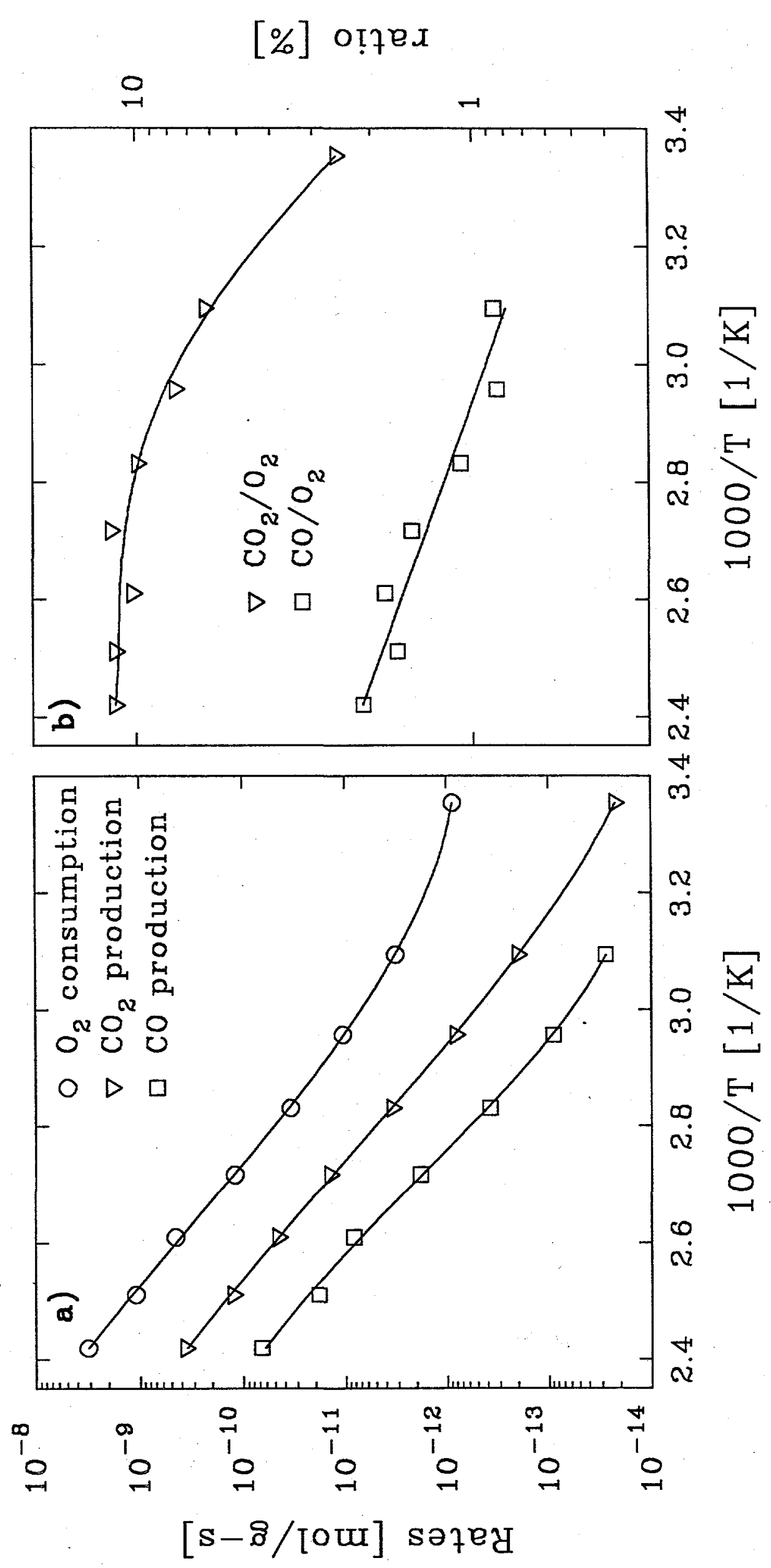



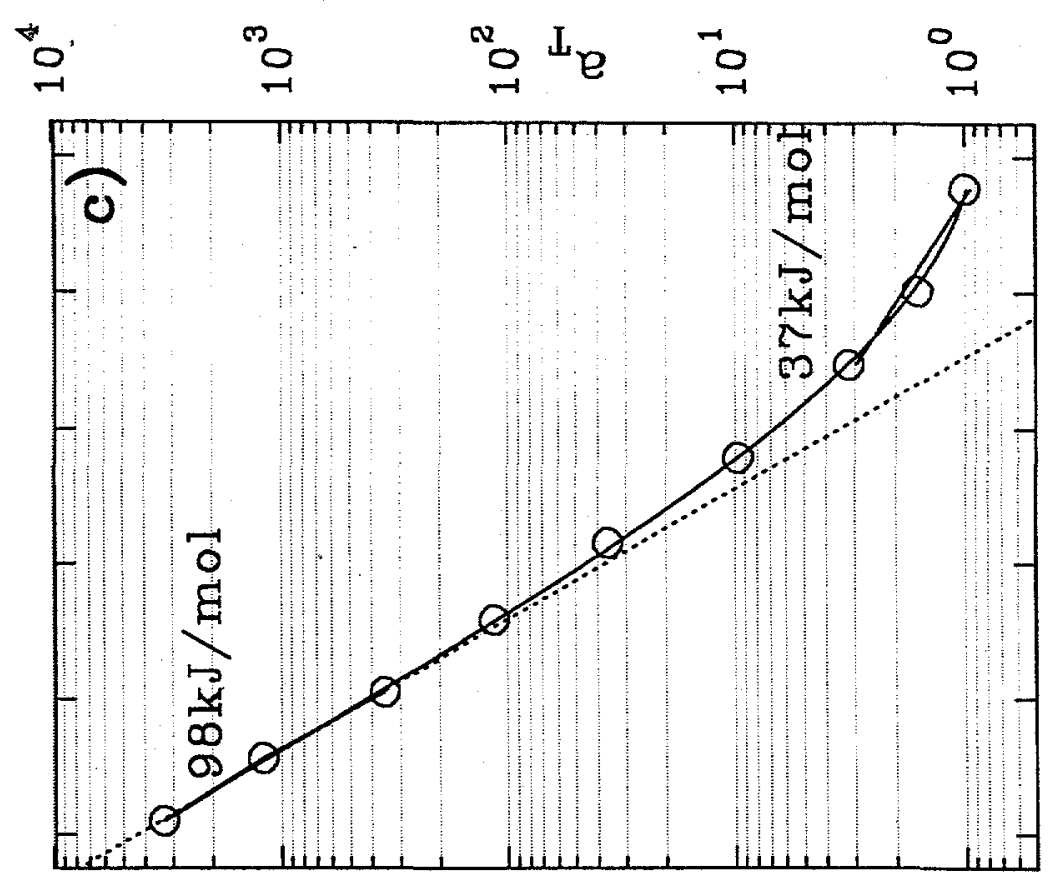

$\dot{m}$

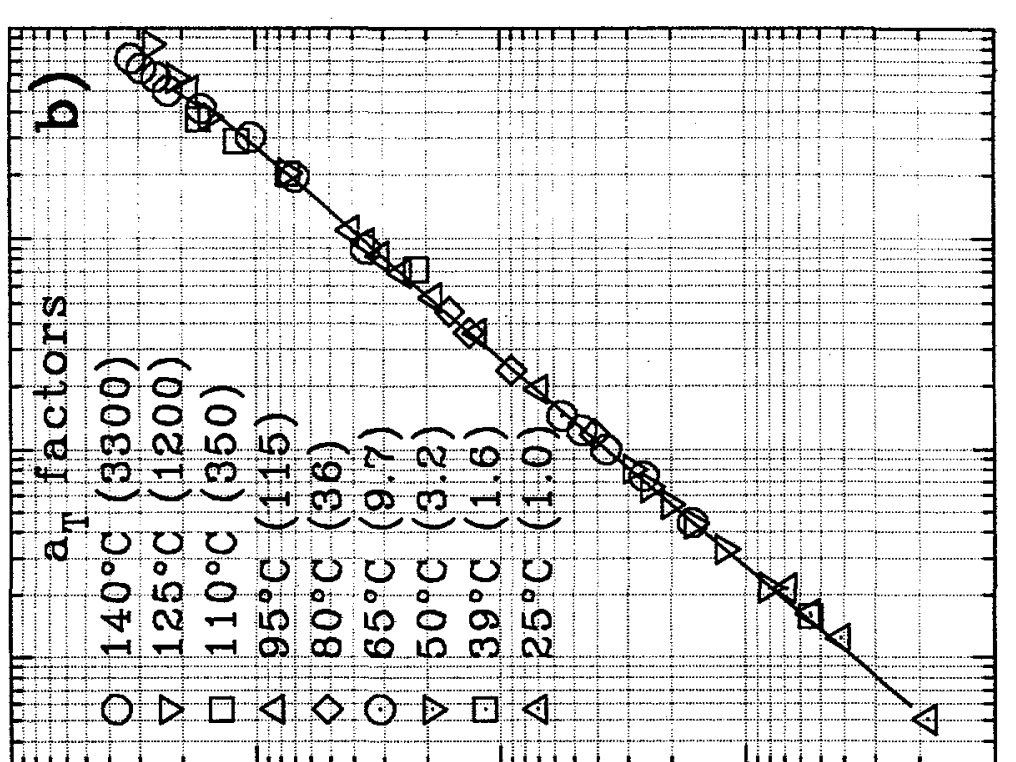

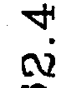

$\infty$

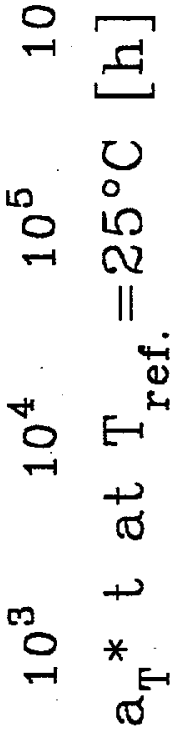

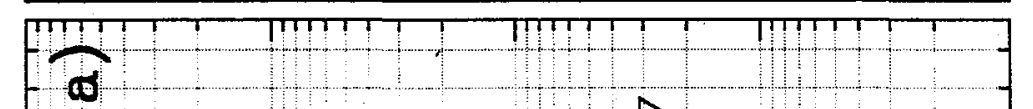

के

के

$\begin{array}{cc}\infty & E \\ \infty & 0 \\ \infty & 0 \\ \infty & 0\end{array}$ 


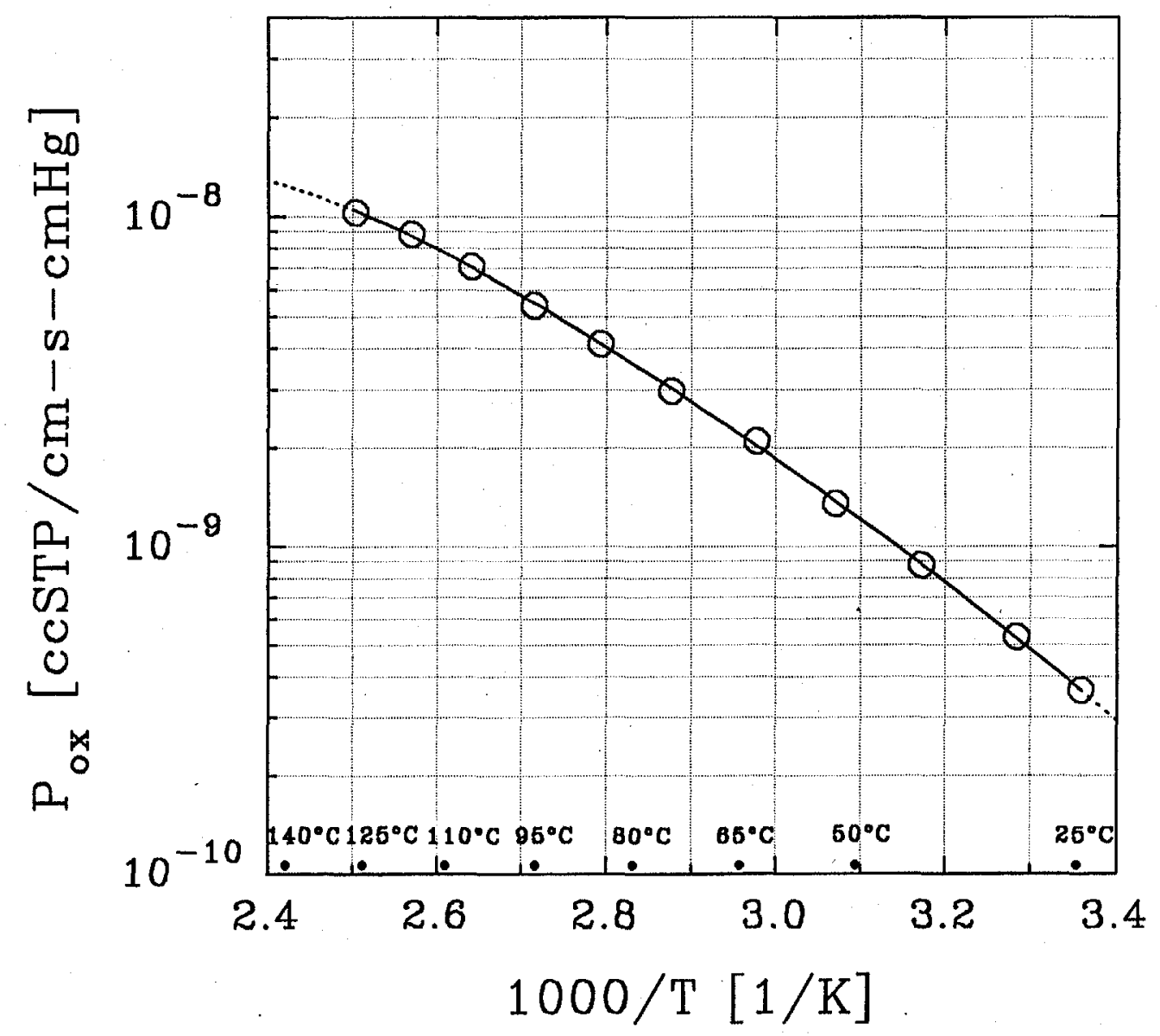




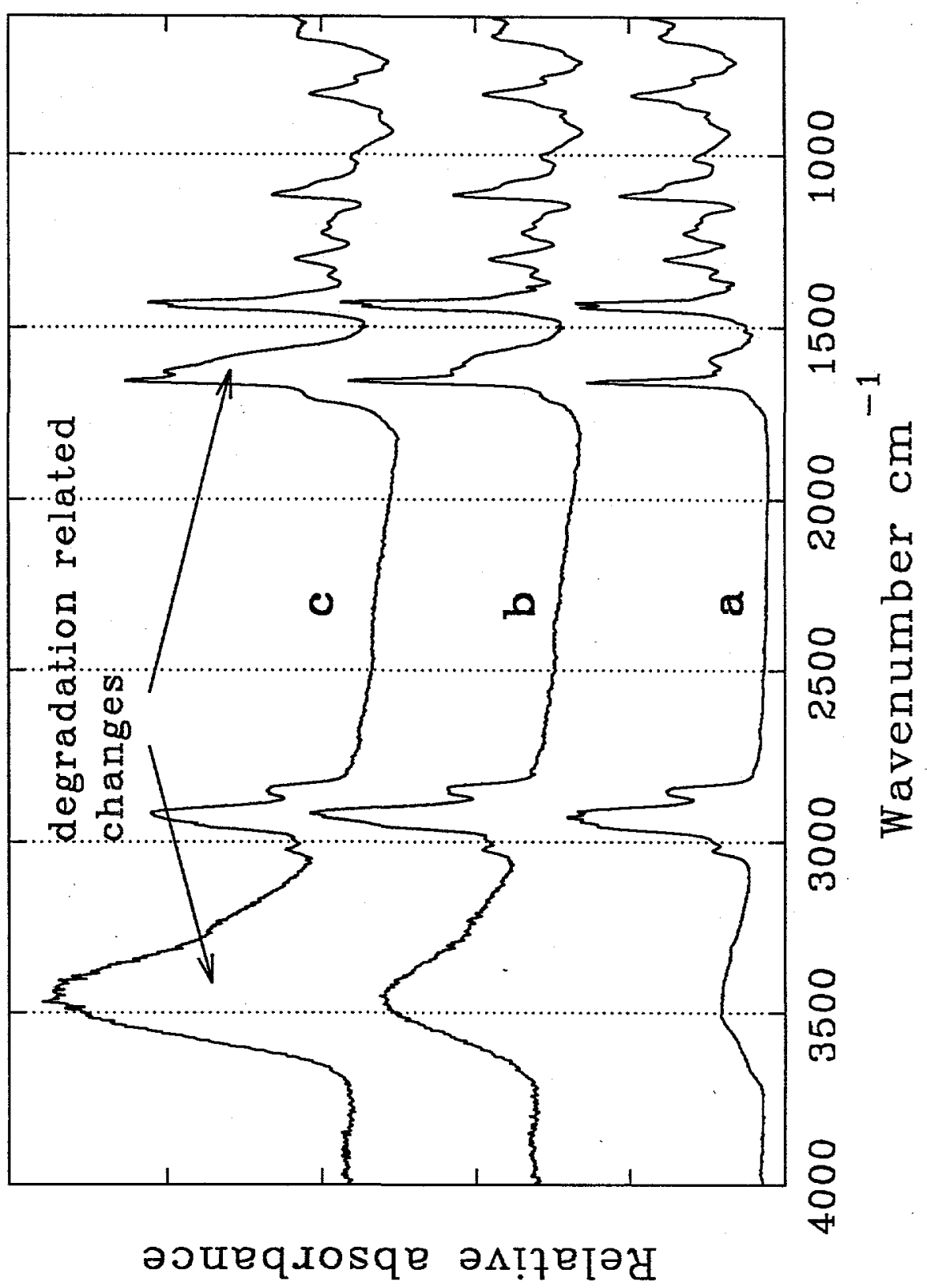




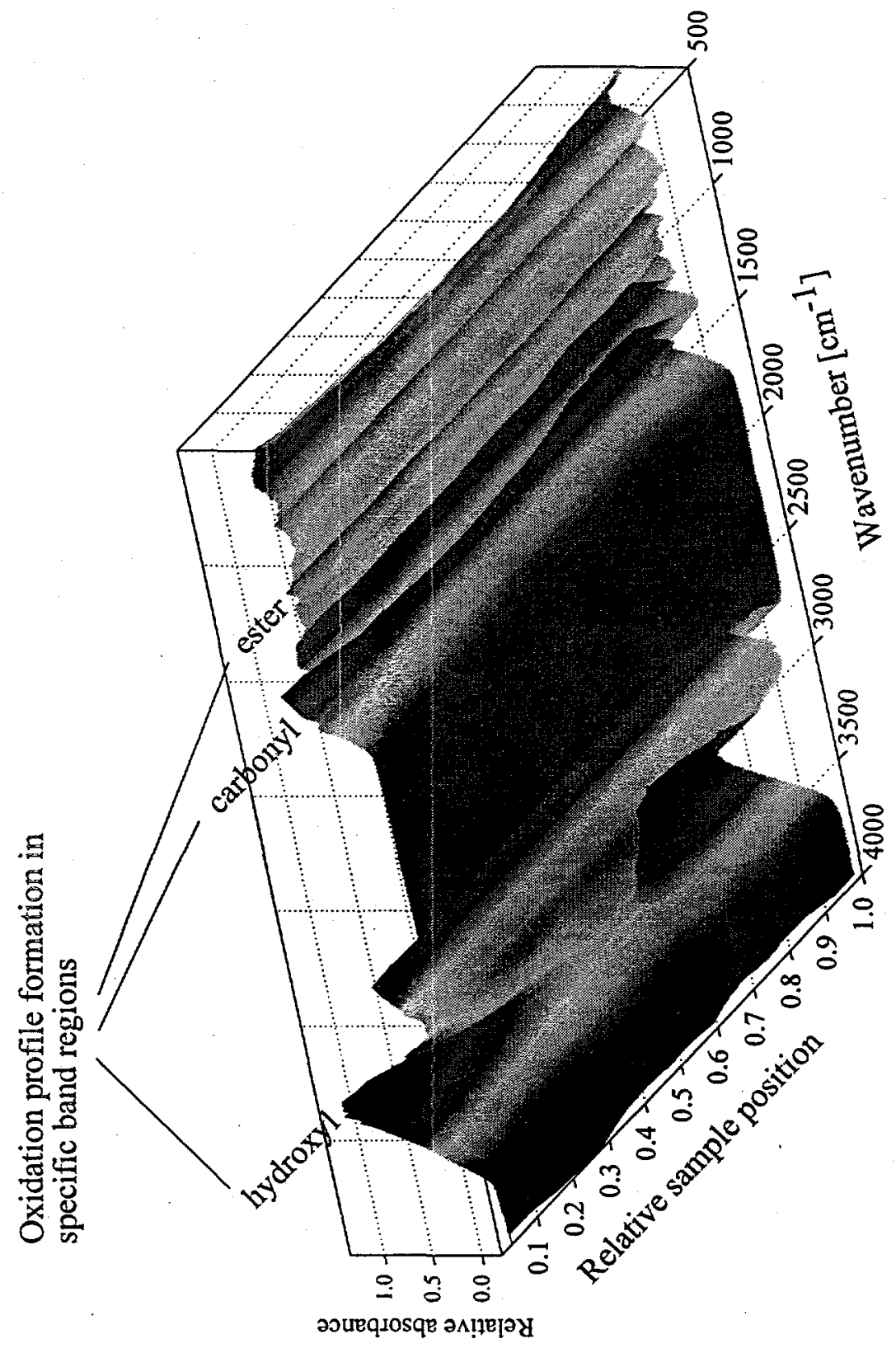




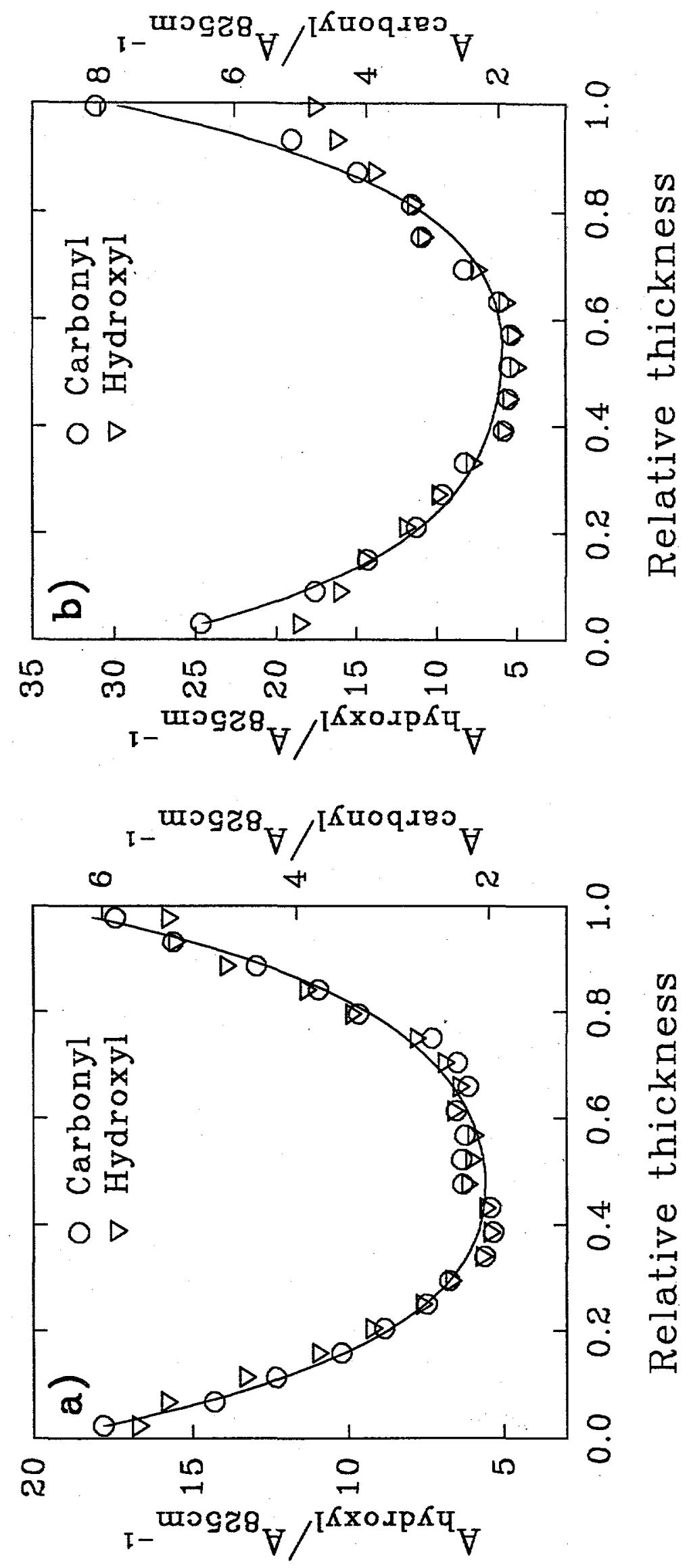



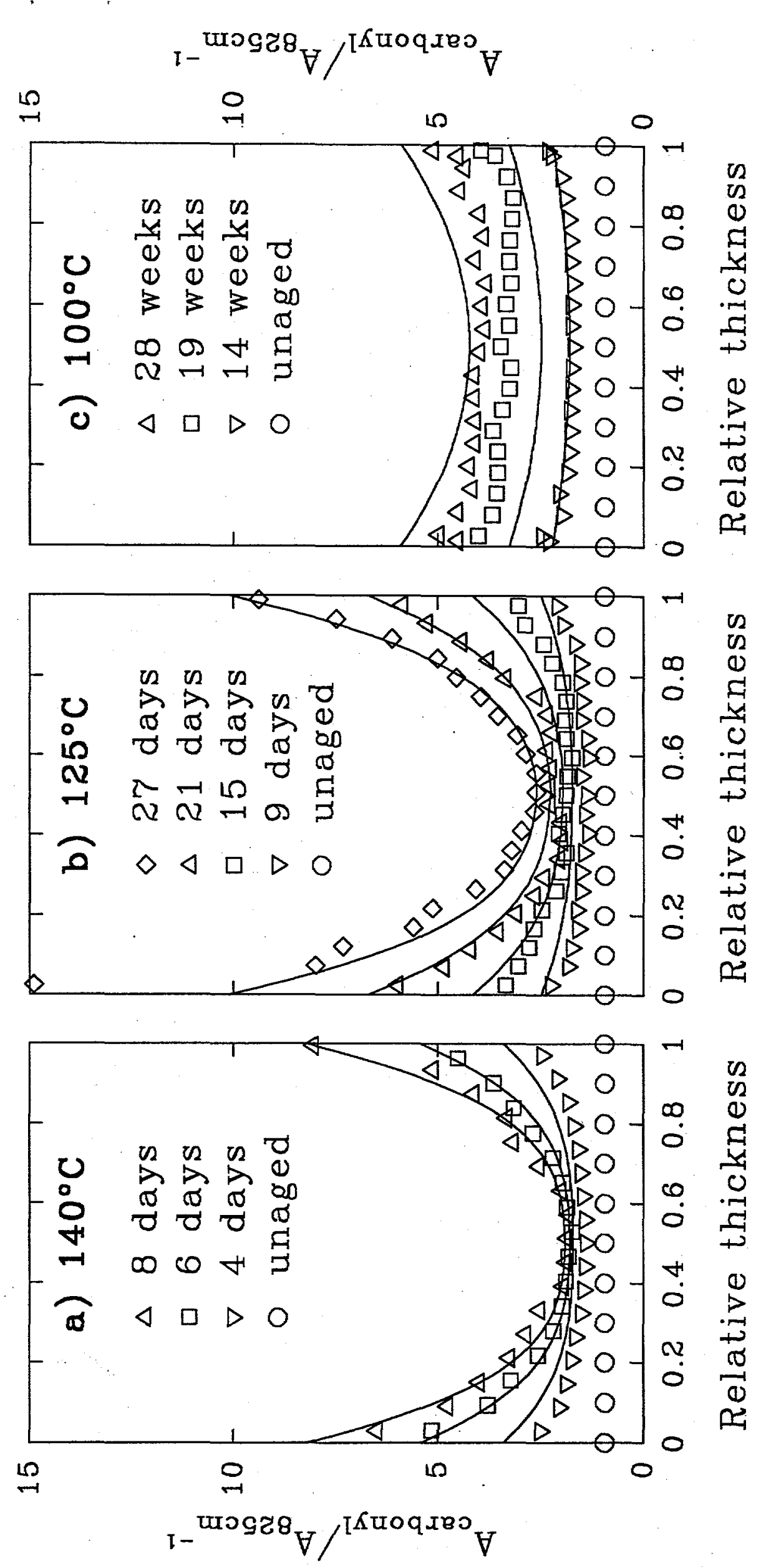


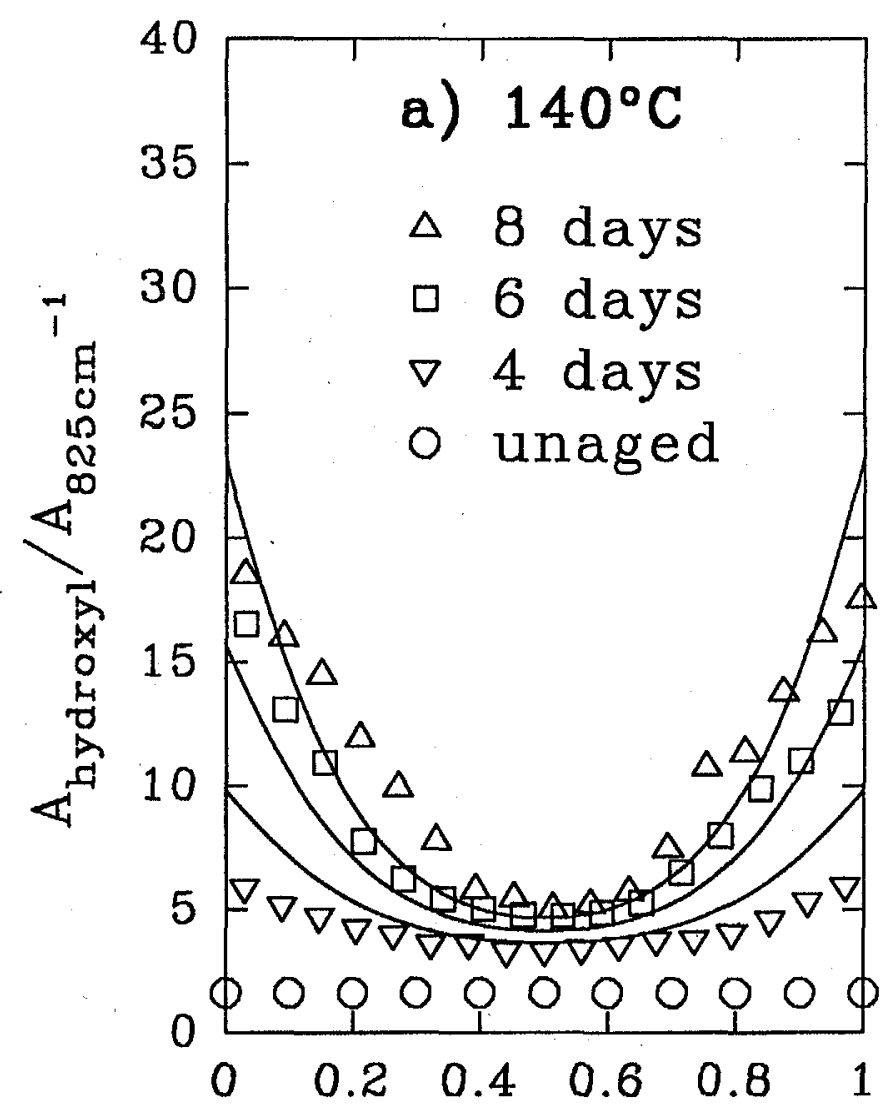

Relative thickness

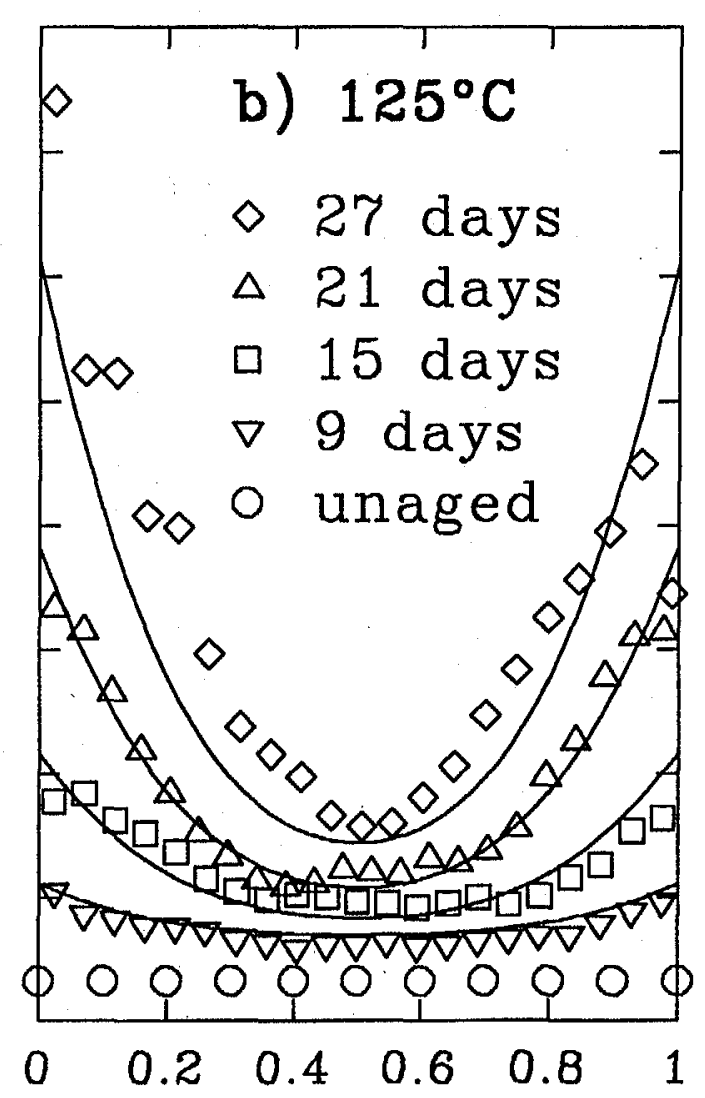

Relative thickness

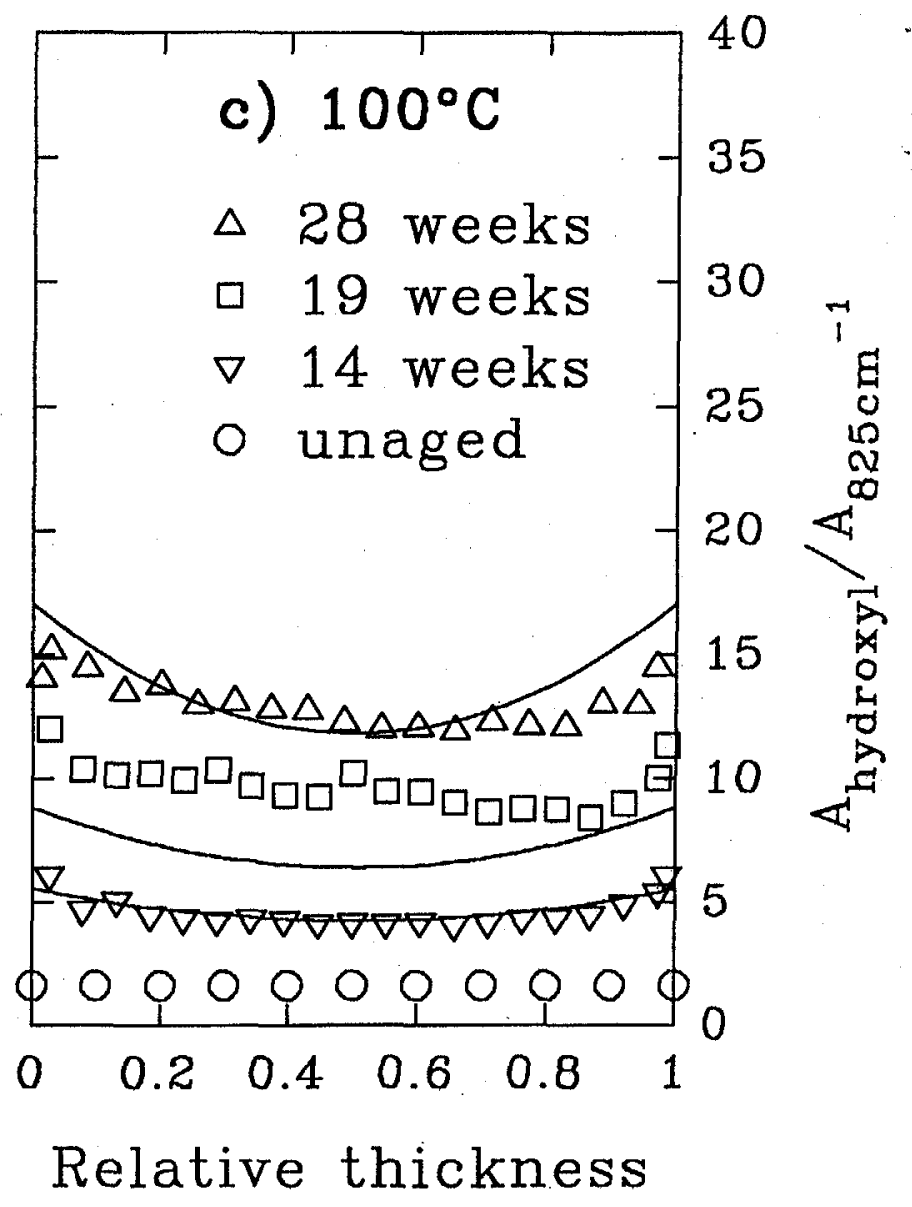



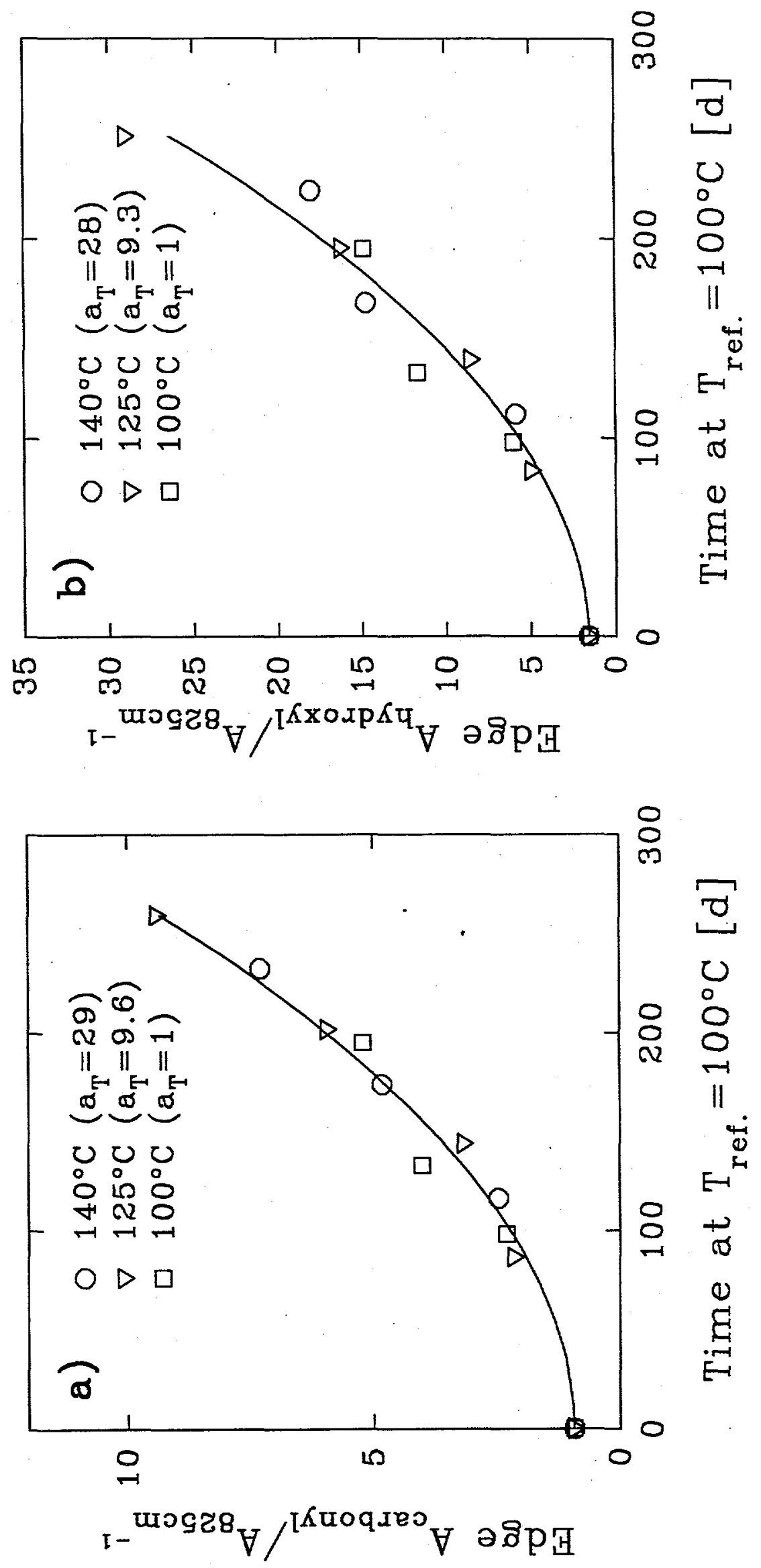


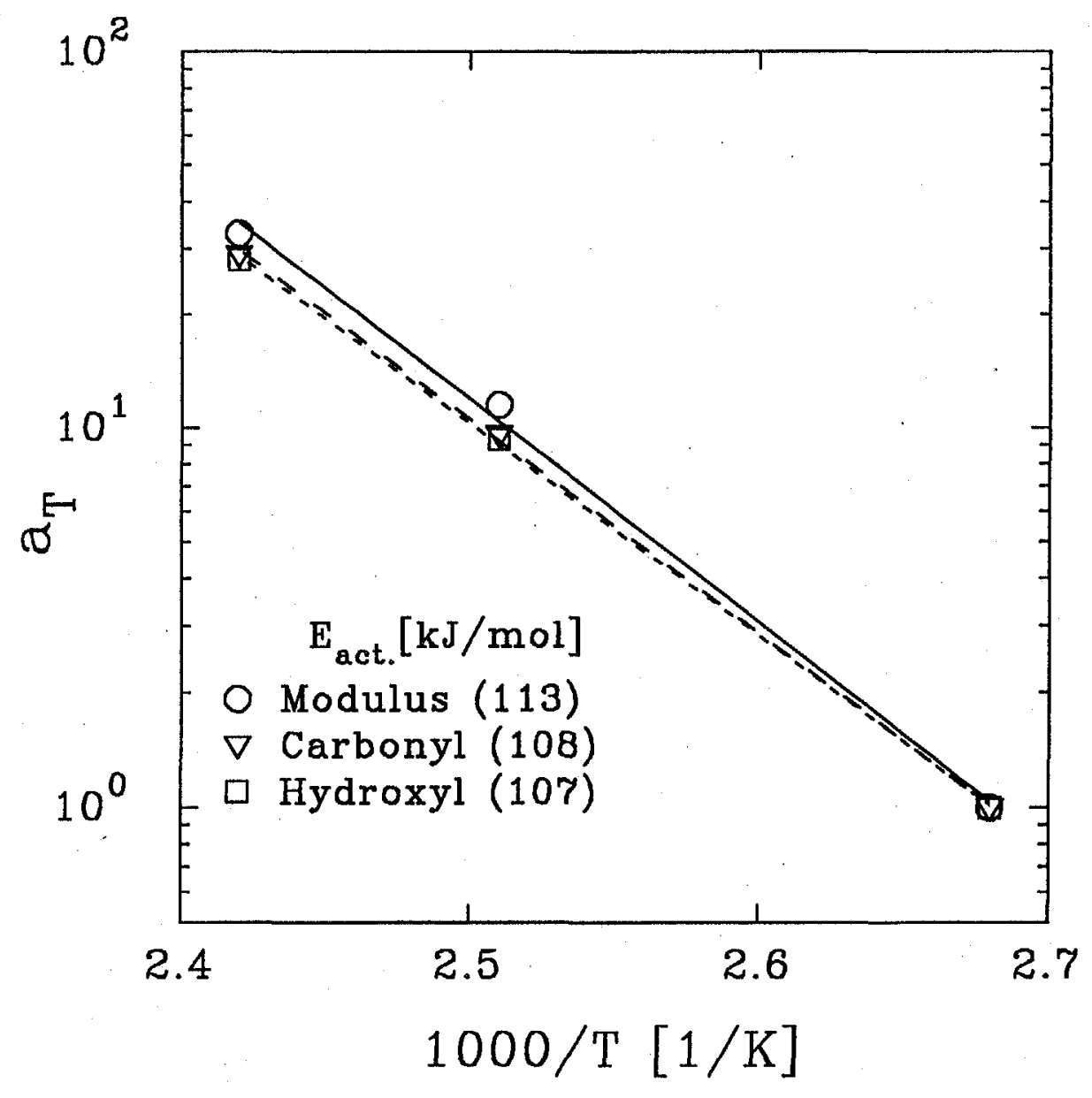




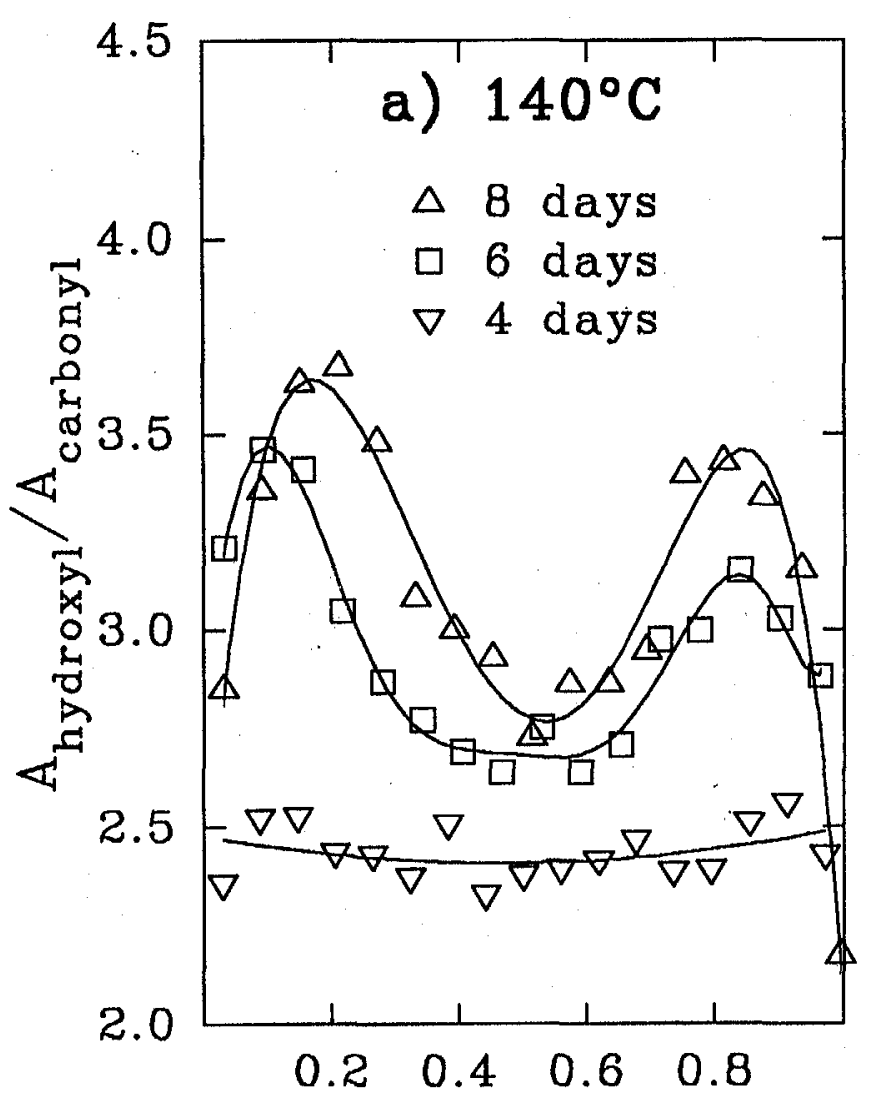

Relative thickness
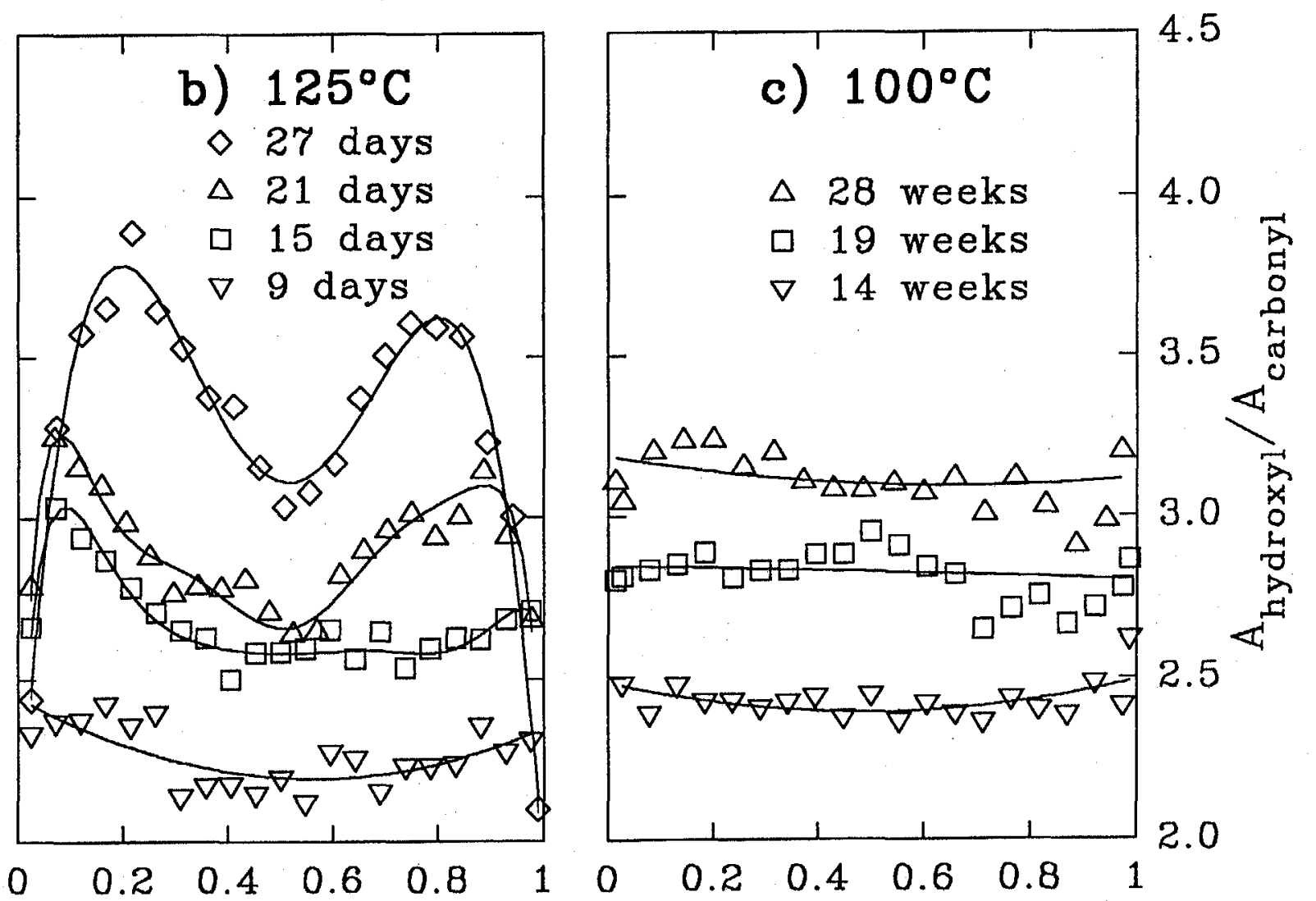

Relative thickness
Relative thickness 


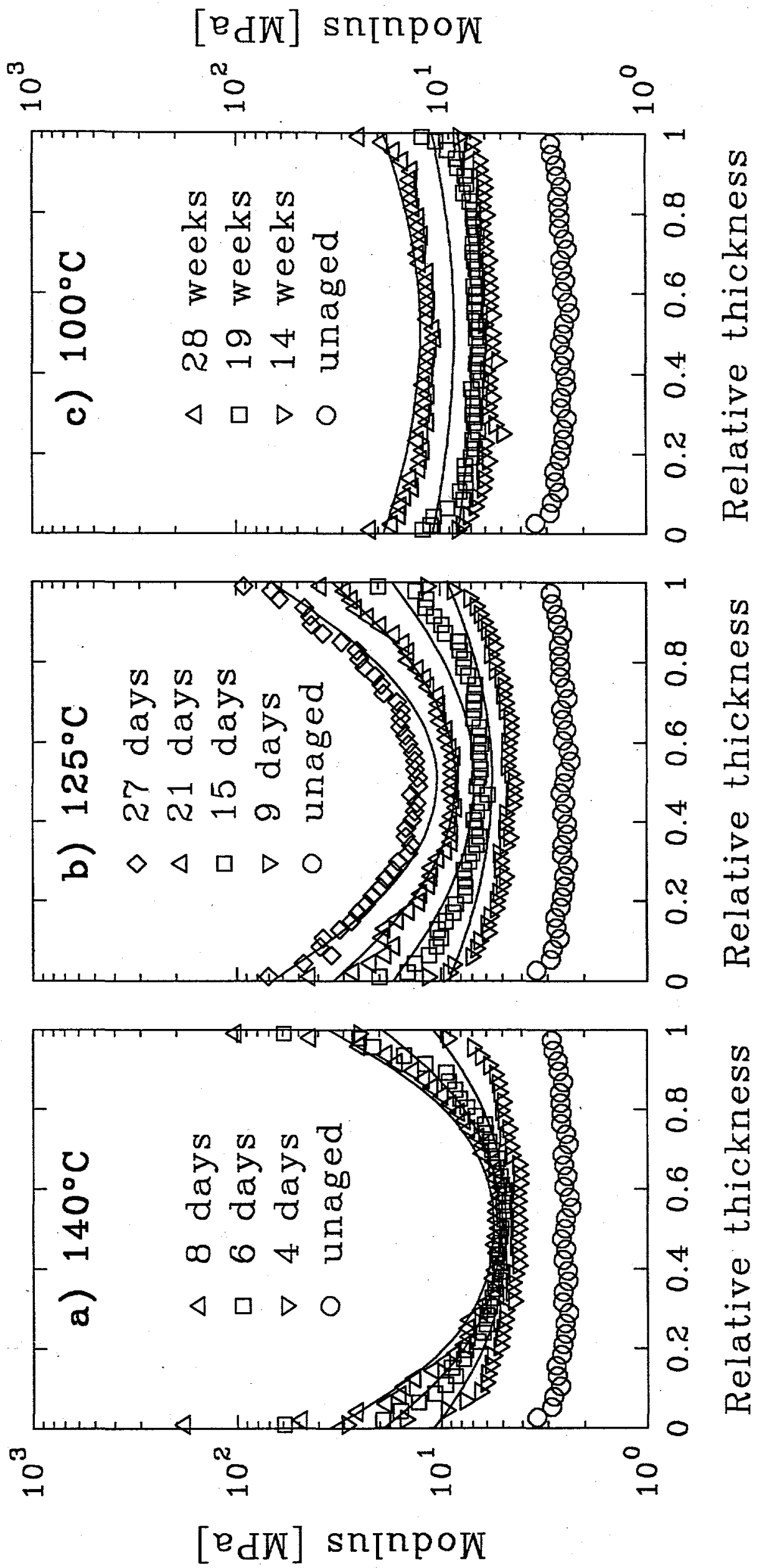




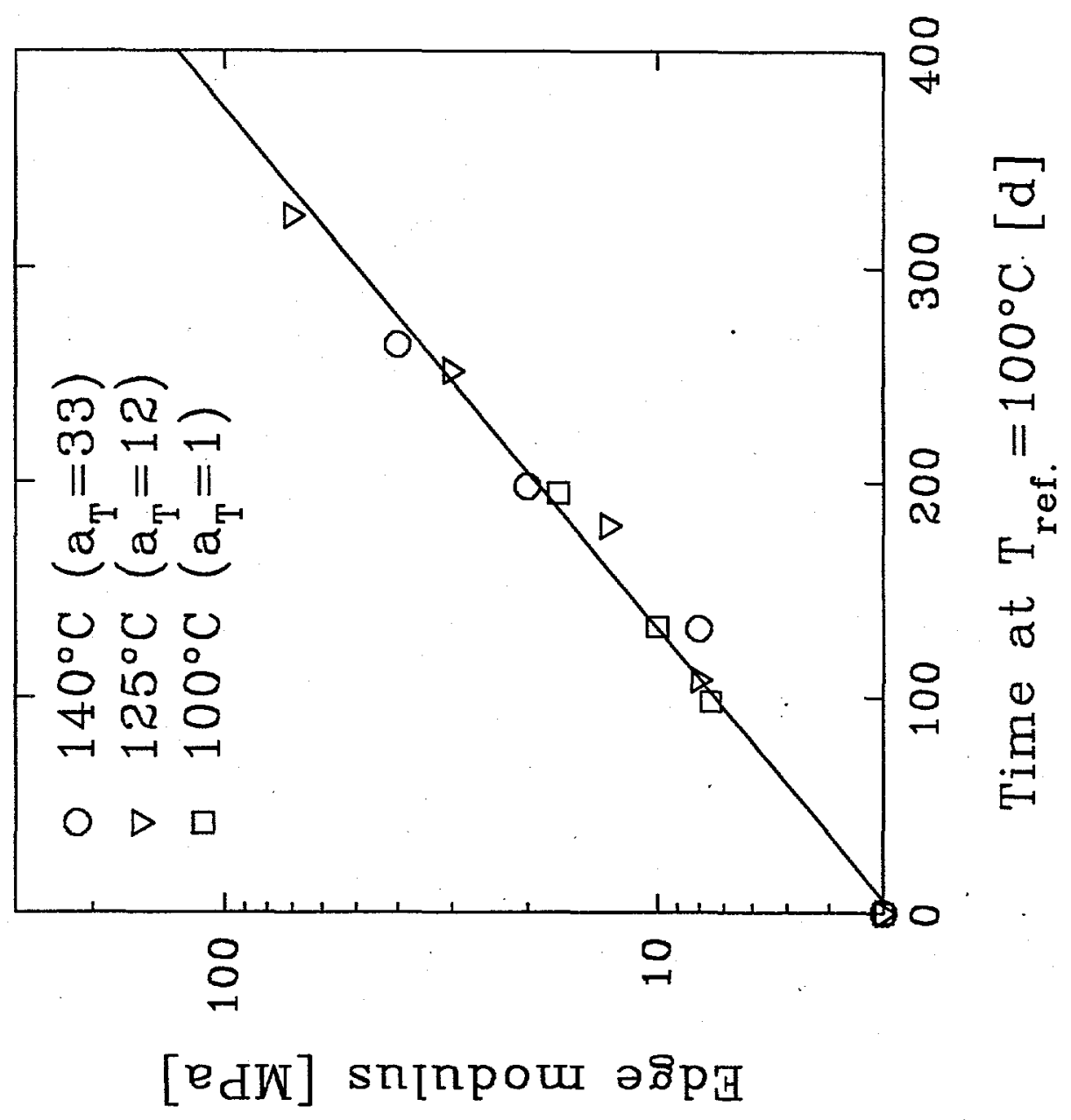



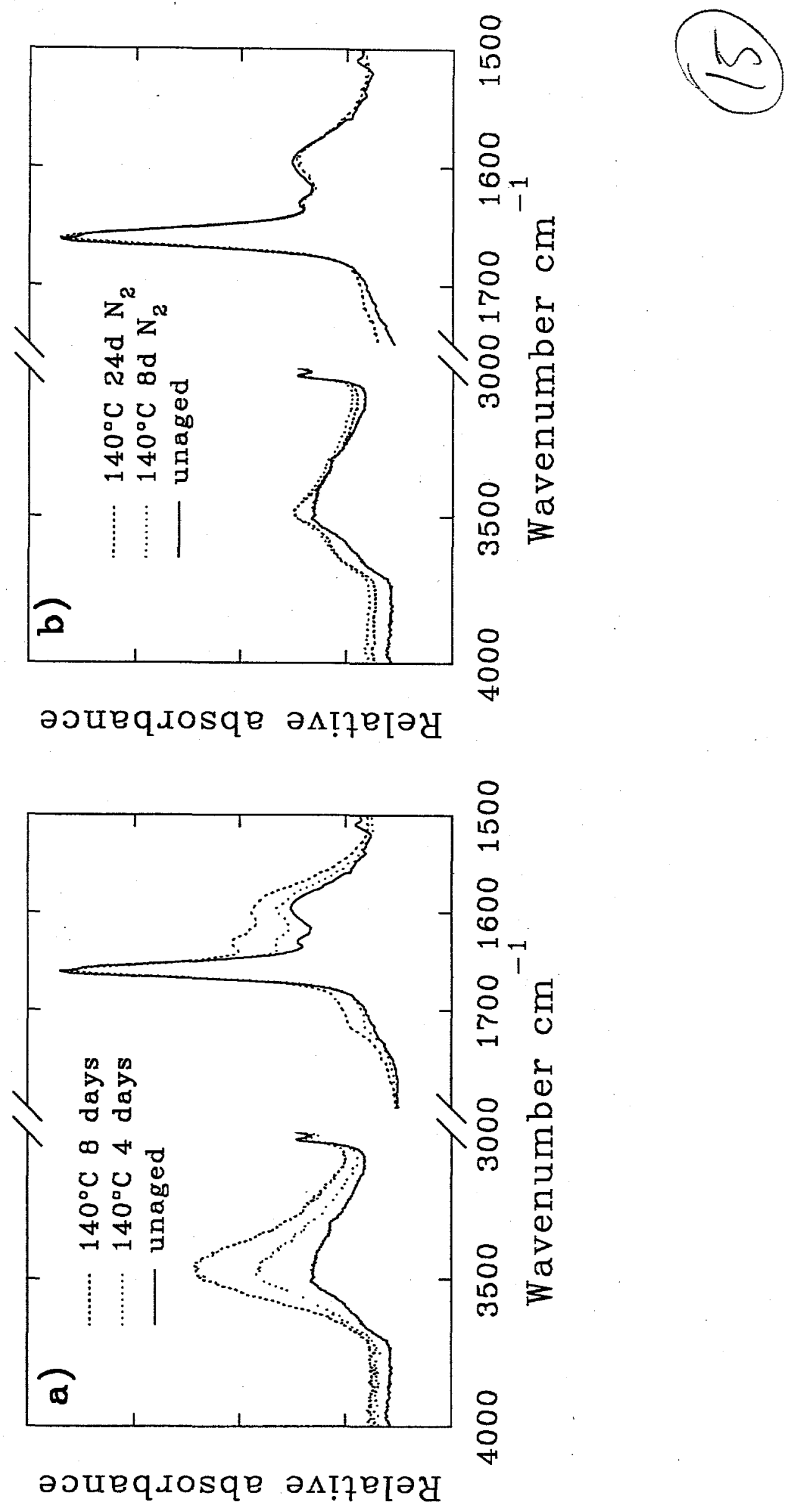


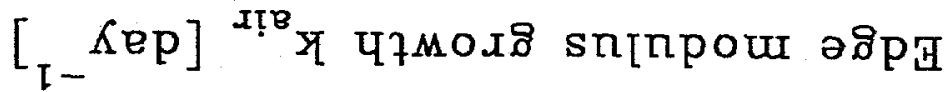
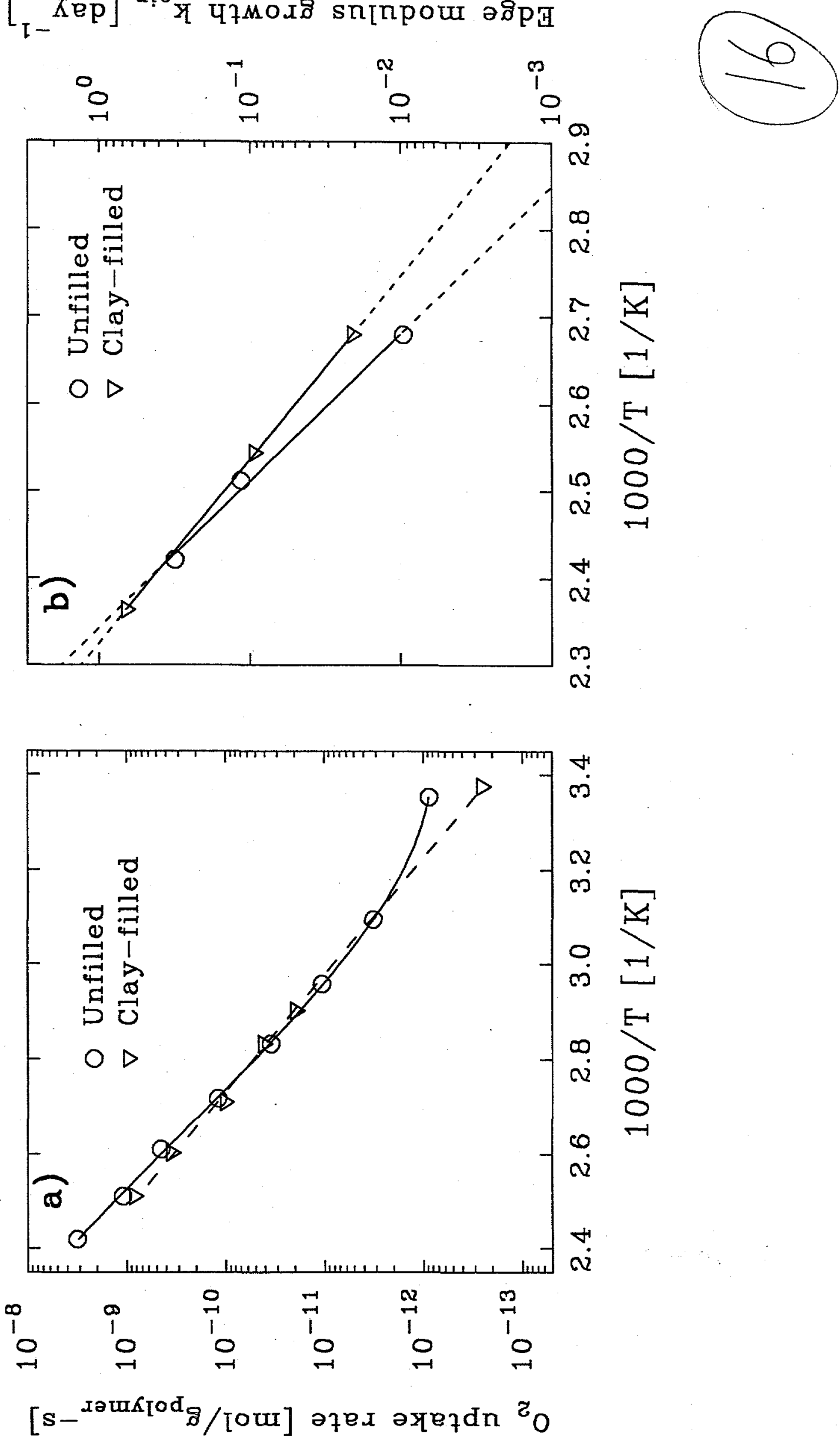